Feedbacks: Financial Markets and Economic Activity

by

Markus K. Brunnermeier, Princeton University Darius Palia, Rutgers Business School

Karthik A. Sastry, Massachusetts Institute of Technology

Christopher A. Sims, Princeton University

Griswold Center for Economic Policy Studies

Working Paper No. 257, August 2019 


\title{
FEEDBACKS: FINANCIAL MARKETS AND ECONOMIC ACTIVITY
}

\author{
MARKUS BRUNNERMEIER, DARIUS PALIA, KARTHIK A. SASTRY, AND CHRISTOPHER A. SIMS
}

\begin{abstract}
Our structural VAR with 10 monthly variables and identified by heteroscedasticity shows that credit and output growth are mostly positively associated. Negative reduced form responses to credit growth are attributed in our model to the monetary policy response to credit expansion shocks. Financial stress, measured by rises in interest rate spreads, is followed by declines in output and shrinkage of credit. We find two distinct sources of financial stress shocks. Neither credit aggregates nor rate spreads provide much advance warning of the 2008-9 crisis, but the spreads improve the model forecasts during the crisis.
\end{abstract}

In the long run, credit aggregates tend to expand faster than GDP. In studies of economic development, the ratio of credit to GDP is sometimes used as a measure of "financial depth," which is thought to contribute positively to economic growth. ${ }^{1}$ On the other hand a number of recent studies claim to have demonstrated a predictive relation between rapid growth of credit and future low GDP growth or higher likelihood of crisis. ${ }^{2}$

Monetary policy has strong effects on GDP growth and also, unsurprisingly, strong effects on credit growth and on spread variables that measure financial stress. Monetary policy also plausibly responds to rapid credit growth or contraction and to changes in spreads. To understand the policy implications of correlations or predictive regressions relating financial variables to GDP growth, it is essential that we understand the extent to which these correlations are generated by, or mediated by, monetary policy itself.

The structural VAR literature on monetary policy effects succeeded in separating two channels of relation between inflation and interest rates - policy-generated increases in interest rates tend to reduce inflation, while interest rates on average endogenously rise with inflation to compensate investors for inflation-generated losses. For the reasons we have listed here, it seems likely that, as with the relation between interest rates and

Date: May 13, 2018.

We are grateful for useful comments from Yuriy Gorodnichenko, Atif Mian, Emil Verner, and Claudio Borio, as well as from seminar participants at Princeton, and the Federal Reserve Bank of New York. This document is licensed under the Creative Commons Attribution-NonCommercial-ShareAlike 3.0 Unported License. http://creativecommons.org/licenses/by-nc-sa/3.0/.

${ }^{1}$ Perspectives on this topic are found, for example, in Shaw (1973), McKinnon (1973), Goldsmith (1969) and Rajan and Zingales (1998). A summary of the related literature is available in World Bank (2012), p.23-25.

${ }^{2}$ For example, Mian, Sufi and Verner (2017), Schularick and Taylor (2012), Jordà, Schularick and Taylor (2014), Borio (2012) and Drehmann and Juselius (2014). 
inflation, there are multiple causal channels connecting spreads, credit aggregates and business activity, and that some of these channels operate with opposite signs. It therefore seems appropriate to estimate a multiple equation model connecting these variables and to imitate if possible the structural VAR literature's approach to unraveling feedbacks in the data.

Much of the existing empirical literature in this area has used short lists of variables and has not attempted to distinguish several channels of interaction between financial variables and the macroeconomy, including the one modulated by monetary policy. Studies of the predictive power of credit growth have primarily used single-equation projection methods (e.g., Mian, Sufi and Verner (2017), Jordà, Schularick and Taylor (2014), and Jordà, Schularick and Taylor (2015)) or binary outcome (i.e., crisis or no crisis) predictive models (e.g., Schularick and Taylor (2012) and Drehmann and Juselius (2014)). ${ }^{3}$ Studies focused on the information in credit spreads have looked extensively at single-equation models (e.g., Lopez-Salido, Stein and Zakrajsek (2015), and Krishnamurthy and Muir (2016)) and reduced form multi-equation models (Gilchrist, Yankov and Zakrajšek (2009) and Gilchrist and Zakrajšek (2012)). Gertler and Karadi (2015) and Caldara and Herbst (2016) introduce credit spread variables into structurally identified, multiple-equation frameworks with monetary policy. But these authors have a narrower focus on identifying and interpreting monetary policy shocks, relative to the rest of the system, and do not discuss the role of credit aggregates. ${ }^{4}$

There have been other studies in this area based on fully interpreted structural dynamic stochastic general equilibrium models, which of course have included estimated effects of monetary policy. ${ }^{5}$ These DSGE models, though, have not considered as many financial variables jointly as we consider here and have imposed more, and more arguable, identifying restrictions than we impose here.

Our model uses monthly data on industrial production (IP), the personal consumption expenditure deflator $(\mathrm{P})$ household credit $(\mathrm{HHC}$ ) business loan credit $(\mathrm{BC})$, money supply

\footnotetext{
${ }^{3}$ Mian, Sufi and Verner (2017) is unique among these for using data outside of identified "crisis episodes." It also contains a small-scale multivariate example, with three variables (real GDP, household credit to GDP ratio, and business credit to GDP ratio), but does not endogenize interest rate dynamics or separately identify monetary policy.

${ }^{4}$ Krishnamurthy and Muir (2016) does look at both aggregates and spreads in the same framework. But their main specifications, single-equation models which can include interactions (non-linear transformations) of credit growth and credit spreads, do not solve the endogeneity problem.

${ }^{5}$ Christiano, Motto and Rostagno (2014), for instance, estimate a monetary DSGE model based on the contract enforcement friction of Bernanke, Gertler and Gilchrist (1999) and find that "risk shocks" which can be measured in observed credit spreads drive a significant portion of U.S. business cycle dynamics. The model uses data on credit spreads and firm credit in addition to "standard" macro aggregates. Del Negro and Schorfheide (2013) provide a detailed comparison of the forecasting performance of this model, a standard Smets and Wouters (2007) DSGE model, and various reduced-form models.
} 
(M1), the federal funds rate (R), a commodity price index (PCM), the 10 year over 3-month Treasury term spread (TS), the Gilchrist and Zakrajšek (2012) corporate bond spread (GZ) and the 3-month Eurodollar over Treasury spread (ES). ${ }^{6}$ The sample period runs from January 1973 to June 2015.

We use the identification-through-heteroskedasticity approach pioneered in economics by Rigobon (2003). This approach assumes that the pattern by which disturbances feed through the economy is stable across time, but that the relative sizes of the independent sources of structural disturbance in the system vary across historical periods. We began modeling time variation in disturbance variance because it is so clearly needed to accurately describe financial variables and some macroeconomic variables. We discovered as we proceeded that we obtained stable, interpretable results from this assumption alone, without the need for the short or long run restrictions on dynamics usually applied to structural VAR's. Details of the model specification are in Section I below.

Here is a qualitative summary of our results. Details and quantitative results are in Section II below.

One of our 10 shocks, indeed the one with the most widespread effects across variables in the system, we interpret as a monetary policy shock. Responses to it match what is usually assumed about the responses to a monetary policy shock in SVAR models. ${ }^{7}$ This shock produces a sustained and non-trivial increase in the interbank spread (ES) variable.

There are shocks, distinct from the monetary policy shock, that move the corporate bond (GZ) and Eurodollar spread (ES) variables, and then later move IP in the opposite direction. These fit the idea that disturbances that originate in financial markets can have macroeconomic effects.

Several shocks generate substantial movement in household and business credit, and all but two of them move industrial production (IP), if at all, in the same direction as the credit aggregates. This fits the idea that most movements in credit aggregates accompany expansion of activity and do not predict future slowdowns. There is a disturbance that moves HHC up, and then with a delay moves IP down, and another that moves BC up, and then with a delay moves IP down. But the downward movement in IP is small and barely statistically significant in both cases. There may be periods where these shocks are important, so that the credit expansion does predict future contraction in business activity, but a quantitative model that can identify such "bad" credit expansions and thereby allow

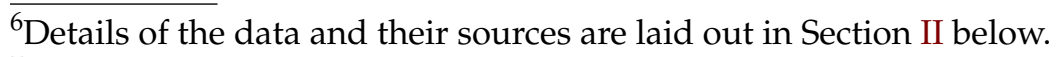

${ }^{7}$ Though we pick the shock we label "monetary policy" by looking at the sign and shape of its impulse responses, this is not the same as the frequently applied "sign restriction" approach to SVAR identification. Sign restriction identification does not lead, even asymptotically, to point identification of responses, whereas our approach, if its assumptions are correct, does provide point identification.
} 
a policy response would have to be multivariate to separate this component of credit growth. These disturbances increase inflation as well as credit, and initially increase IP, so it is natural that monetary policy responds to them by increasing interest rates. Our model implies that if the shocks were accompanied by monetary policy holding interest rates fixed, the decline in IP following the shocks would disappear, though of course at the cost of increased inflation.

We can also consider whether a monetary policy maker, who could identify a credit shock that predicted a future output decline, could use that knowledge to suppress the effect of the credit expansion. Since contractionary monetary policy is estimated to have negative effects on both credit and output growth, suppressing the credit expansion would only increase the subsequent output decline. Suppressing the predicted output decline via expansionary monetary policy would be feasible, but of course would increase, not decrease, the credit expansion.

The limited predictive value for credit aggregates in our system may appear difficult to reconcile with the results of previous studies with smaller models that have found substantial predictive value for credit aggregates in forecasting future business activity or future crises. In Section III we show that results in the literature based on smaller models, which show credit expansion predicts slow or negative future output growth, are not inconsistent with our model. Our model implies that these small-model results may be misleading if interpreted causally.

In Section IV we conduct pseudo-out-of-sample forecasting experiments to see what predictive value arises from including the spread and credit aggregate variables in the system. We find that the model gives little advance warning of the 2008-9 crash, whether or not the financial variables are included, but that the model tracks the course of the recession considerably better when they are included ${ }^{8}$. Most of the improved tracking of the crisis period comes from including the spread variables, not the credit aggregates.

In Section $V$ we summarize variations on our model that we have investigated to check robustness of results, though the details of most of these variations appear in the online appendix.

\section{Models And Estimation Methods}

This section describes our empirical approach. The first two parts introduce our multivariate time series models, and the third part describes our Bayesian estimation method.

${ }^{8}$ This is similar to the conclusion of Del Negro and Schorfheide (2013), who compare a New Keynesian DSGE model with and without financial frictions of the form in Christiano, Motto and Rostagno (2014) and Bernanke, Gertler and Gilchrist (1999). 
I.1. The basic model. We specify structural vector auto-regressive (SVAR) models with variances changing at exogenously specified dates. They can be described by the system of dynamic stochastic equations

$$
A_{0} y_{t}=\sum_{j=1}^{p} A_{j} y_{t-j}+C+\epsilon_{t}
$$

where $y_{t}$ is an $n \times 1$ vector of observed variables, $A_{0}$ is an $n \times n$ matrix which determines simultaneous relationships, the $A_{j}$ are $n \times n$ matrices of coefficients at each lag $j, C$ is an $n \times 1$ vector of constants, and $\epsilon_{t}$ is a vector of independent shocks. In the base model, these are Gaussian (normally distributed).

We exogenously separate the time span $\{1 \ldots T\}$ into $M$ subperiods and set

$$
\mathbb{E}\left[\epsilon_{t} \epsilon_{t}^{\prime}\right]=\Lambda_{m} \quad \text { if } t \text { is in period } m \in\{1 \ldots M\}
$$

where $\Lambda_{m}$ is a diagonal matrix. The variance of the structural shocks changes across periods, but the dynamic relationship among the variables, as determined by $A_{0}$ and the $A_{j}$, remain fixed. In different terms, the impulse responses to structural shocks will have the same shape across variance periods, but their scales will vary. Our choice of variance regimes in estimated models (discussed in Section II and presented in Table 2) is motivated by observed variation in the time series and outside knowledge about policy changes.

We could fairly easily have allowed for regime changes to evolve as a Markov-switching stochastic process, as in Sims and Zha (2006). However, so long as the regimes are persistent, few in number, and well-determined by the data, inference about the model's dynamics is not likely to be strongly affected by conditioning on the regime switch dates as if known. ${ }^{9}$

Our set-up can also be illustrated in the reduced form,

$$
y_{t}=\sum_{j=1}^{p} B_{j} y_{t-j}+D+u_{t}
$$

with

$$
\mathbb{E}\left[u_{t} u_{t}^{\prime}\right]=A_{0}^{-1} \Lambda_{m}\left(A_{0}^{-1}\right)^{\prime} \quad \text { if } t \text { is in period } m \in\{1 \ldots M\}
$$

\footnotetext{
${ }^{9}$ Of course it is plausible that the variance regime switches are not only random, but endogenously determined. Allowing for that would greatly complicate the model and, since the regime switches are few in the data, might leave the nature of the regime switch endogeneity ill-determined by the data. We leave this to future research.
} 
Some normalization is required, as we could multiply the rows of $A_{0}$ and $\Lambda$ by scale factors without changing the implied behavior of the data. We impose the restriction

$$
\frac{1}{M} \sum_{m=1}^{M} \lambda_{m, i}=1 \quad \forall i \in\{1 \ldots n\}
$$

where $\lambda_{m, i}$ is the $i$ th diagonal element of $\Lambda_{m}$. This makes the cross-period average structural variance 1 in each equation. It can be shown that, given such a normalization and the technical condition that each pair of equations differs in variance in at least one period, we can uniquely identify all $n^{2}$ parameters of $A_{0}$ (up to flipping the sign of an entire row, or permuting the order of rows). ${ }^{10}$ Thus the variance switching eliminates the need for arguable linear restrictions on the $\left(A_{i}\right)_{i=0}^{p}$, such as "short-run" restrictions on contemporaneous responses in $A_{0}$ or "long-run" restrictions on the sums of coefficients in the $\left(A_{i}\right)_{i=1}^{p}$. Avoiding such restrictions on $A_{0}$, while still maintaining full identification, is a particularly appealing feature for a model including financial time series which would plausibly react to all shocks immediately at the monthly or lower frequency.

While under the model's assumptions the impulse responses of the system will be consistently estimated in large enough samples, the model does not give names to the shocks that drive it. In our later analysis, we pick out one of our 10 estimated shocks as a monetary policy shock, and two others as reflecting disturbances originating in financial markets. Our choices of names for these shocks reflect a priori assumptions about what shocks with these names should look like, in terms of the responses they generate. This is similar in spirit to the "sign restriction" approach to SVAR identification. However sign restrictions on impulse responses by themselves do not provide point identification, whereas our approach does allow point identification.

Aside from flexible identification of impulse responses, another benefit of our method is efficiency. For the same reasons as standard GLS (Generalized Least Squares), our method prevents periods of large shocks from inefficiently dominating the likelihood.

I.2. Non-normality in the error distribution. The previous section's correction for heteroskedasticity will work best if volatilities mainly change between persistent episodes or regimes. But it does not allow for the possibility of a few isolated large disturbances

$\overline{10}$ The intuition is that if $\Sigma_{j}$ is the reduced form residual covariance matrix for period $j$, the expression

$$
\Sigma_{i}^{-1} \Sigma_{j}=A_{0}^{\prime} \Lambda_{i}^{-1} \Lambda_{j}\left(A_{0}^{-1}\right)^{\prime}
$$

has the form of an eigenvalue decomposition, with the columns of $A_{0}^{\prime}$ the eigenvectors. As long as the eigenvalues, the diagonal elements of $\Lambda_{i}^{-1} \Lambda_{j}$, are unique (i.e., there is no $k, l$ such that $\lambda_{j, k} / \lambda_{i, k}=\lambda_{j, l} / \lambda_{i, l}$ ), the rows of $A_{0}$ are therefore uniquely determined up to scale once we know $\Sigma_{i}$ and $\Sigma_{j}$. A more formal proof of this can be found, for instance, in Lanne, Lütkepohl and Maciejowska (2010). 
or outliers. For instance, the bankruptcy of Lehman Brothers in October 2008 and the 650 basis point drop in the Federal Funds rate from April to May 1980 generate outliers of around 6 standard deviations that do not disappear when we allow variance-regime switches. To guard against such large shocks distorting inference, we consider a specification in which structural errors $\epsilon_{t}$ have Student $t$ distributions. ${ }^{11}$

In the model notation, we can introduce random parameters $\xi_{i, t}$ such that

$$
\epsilon_{i, t} \sim \operatorname{Normal}\left(0, \lambda_{i, t} \xi_{i, t}\right)
$$

We can also think of these objects as shocks which capture, in a simple way, a highfrequency component of volatility that has no persistence across time or correlation across equations.

Giving the $\xi_{\text {it }}$ an inverse-gamma distribution, i.e.

$$
\xi_{i, t} \sim \text { Inverse Gamma }(\text { shape }=\alpha / 2, \text { rate }=2 / \alpha) .
$$

implies that each $\epsilon_{i, t}$ has an independent Student- $t$ distribution with $\alpha$ degrees of freedom and unit scale. ${ }^{12}$ We chose the degrees of freedom of the $t$ distribution to be 5.7, by fitting the sample distribution of residuals for the Gaussian-errors model. ${ }^{13,14}$

I.3. Econometric methodology. Equations (1) and (2), combined with the normalization of variances, describe a model with $n^{2}$ free parameters in $A_{0},(M-1) n$ free parameters in the $\Lambda_{m}$, and $n^{2} p$ free parameters in the $A_{j}$. The model with $t$-distributed disturbances has another $n T$ parameters. ${ }^{15}$ We use Bayesian methods to update beliefs about the parameters conditional on observed data $\left\{y_{1} \ldots y_{T}\right\}$ and initial conditions $\left\{y_{-p-1} \ldots y_{0}\right\}$.

\footnotetext{
${ }^{11}$ The mixture-of-normals assumption has been used in the time series literature to better model large movements in macro variables. Lanne and Lütkepohl (2010) introduce a maximum likelihood approach to estimating a discrete normal mixture SVAR model, and Chiu, Mumtaz and Pinter (2015) describe a Bayesian Gibbs sampling algorithm with an application to a model with stochastic volatility for U.S. data. Chib and Ramamurthy (2014) present a Gibbs sampling method for estimating a DSGE model with $t$-distributed shocks and Cúrdia, Del Negro and Greenwald (2014) find that the assumption improves the fit of a New Keynesian DSGE model that already includes low-frequency volatility changes.

12 The appendix reports results from an an alternative case with $\xi_{i, t}$ as independent $k$-multinomial, so that the distribution is a finite mixture of normals.

${ }^{13}$ Of course we could have treated the degrees of freedom of the $t$ distribution as another parameter in our MCMC iterations. Here, as in a number of other cases of possible extensions of the parameter list, the likely improvement in fit and effect on conclusions did not seem to justify the increased computational burden.

${ }^{14}$ All that matters to the likelihood is the shape of these distributions, not their scale, since $A_{0}$ can absorb differences in scale. However because our prior on $A_{0}$ is not scale invariant, results might have been slightly different if we had used the fitted scale for the $t$-distributed shocks (.78), instead of the unit scale..

${ }^{15}$ As mentioned previously, the $\xi_{\text {it }}$ can equally well be called parameters or shocks. The fact that there are so many of them does not mean they cause difficulties in estimation, because each has a specified distribution. This is a special case of the general point that Bayesian inference treats parameters and shocks symmetrically. They are all unknown objects with distributions.
} 
For $A_{0}$ we specify independent Gaussian priors on all elements, centered around 100 times the identity matrix, with standard deviation 200. For $\lambda_{\cdot, i}=\left\{\lambda_{1, i} \ldots \lambda_{M, i}\right\}$, the vector of variances in each equation $i$, we put a Dirichlet prior (with $\alpha=2$ ) on $\lambda_{,, i} / M$. This restricts each of the relative variances to lie in $[0, M]$ (where $M=10$ in our main model), centers the prior on equal variances, and enforces our normalization that for each structural shock the relative variances average to one across periods. We use a variation of the "Minnesota prior" described in Sims and Zha (1996) on the reduced form parameters in the matrices $B_{j}$ and $D$ of equation (3). These priors, described in more detail in Appendix 1 , center belief loosely around independent random walks in each variable. They also imply that constant terms should not interact with near unit roots to imply rapid trend growth and that, if the dynamics are stationary, initial conditions should not be too far from the model's implied unconditional means. Conditional on $A_{0}$, these priors imply Gaussian priors on the $A_{j}$ matrices.

In the case with normal structural shocks, we sample from the posterior distribution for these parameters in a two-step process that exploits the fact that, conditional on knowing $A_{0}$ and $\left\{\Lambda_{1} \ldots \Lambda_{M}\right\}$, we can treat (1) as a system of $n$ independent linear regressions which can be estimated with weighted least squares. In the first step of the sampling process, we use a Metropolis algorithm with Gaussian jump distribution ${ }^{16}$ to sample the elements of $A_{0}$ and $\left\{\Lambda_{1} \ldots \Lambda_{M}\right\}$ using the likelihood integrated over the $A_{j}$ (which is available analytically). Then, after drawing a large MCMC sample from the marginal posterior distribution of $A_{0}$ and $\left\{\Lambda_{1} \ldots \Lambda_{M}\right\}$ we can, for each of the $A_{0}, \Lambda$ draws, sample from the coefficients in the $A_{j}$ which have a known conditional normal distribution.

The model with $t$-distributed shocks requires a more involved method, a (non-standard) Metropolis-in-Gibbs algorithm. The first part of the algorithm, a Monte Carlo update of $A_{0}$ and $\left\{\Lambda_{1} \ldots \Lambda_{M}\right\}$ conditional on the $\xi_{i, t}$ and integrated over the $\left(A_{j}\right)_{j=1}^{p}$, is just as in the normal shocks model. But now we need to draw $\left(A_{j}\right)_{j=1}^{p}$ after each draw of $\left(A_{0}, \Lambda\right)$ to form implied normalized residuals $\epsilon_{i, t}$. The $\xi_{i, t}$, conditional on the $\epsilon_{i, t}$ are distributed independently across $i$ and $t$, allowing us to draw directly from their exact conditional posterior distribution. The process is repeated recursively. Appendix 2 describes the mechanics of the both algorithms in more detail, and Appendix 3 reports diagnostic evidence of its convergence to randomly sampling the model posterior.

For a given set of model parameters, we could change the sign of the coefficients in an equation (a row of $\left.\left(A_{0}, A_{1}, \ldots\right)\right)$ or change the order of the equations (permute the

\footnotetext{
$\overline{{ }^{16} \text { See Gelman et al. (2014), section } 11.2}$
} 
rows of $\left.\left(A_{0}, A_{1}, \ldots\right)\right)$, without changing the implied distribution of the data. The likelihood maximum therefore recurs through the parameter space at every permutation or sign change of the parameters. This means that a complete MCMC sampling of the posterior distribution would show identical impulse response distributions for all shocks, all centered at zero response - but only if the prior itself were invariant to permutations of the orderings or signs of the equations.

Our prior, because it puts positive prior means on the diagonal elements of $A_{0}$, is not invariant to permutations and scale changes of equation coefficients. As a result, we find no indication that our posterior sampling scheme is distorting results by not eliminating draws that are permutations or sign-switches of each other. We have verified that there are local peaks in the posterior at points in the parameter space that permute the ordering of variables but otherwise match the parameter values at the global peak. The prior is smaller by more than $100 \log$ points at these permutations of the global posterior model, though, and this is enough to prevent even our MCMC samples of hundreds of thousands of draws from wandering into the neighborhoods of these local peaks. Nonetheless these methods, if applied on data for which identification did not emerge as strongly, might need to test for and eliminate permuted or sign-switched models. ${ }^{17}$

This probability model implies prior and posterior distributions for all (potentially nonlinear) transformations of the coefficients, including the reduced form coefficients $B_{j}$ and the impulse response functions for variable $i$ to each shock $j$. In all reported results, following Sims and Zha (1999), we report horizon-by-horizon $68 \%$ and $90 \%$ posterior density regions as "error bands."

\section{DATA AND RESUltS}

Our main specification uses monthly data on 10 time series (listed in Table 1) from January 1973 to June 2015. We include data from the 1970s because they are a valuable source of variation in the time series and because correction for time-varying variance can account for what otherwise might be interpreted as regime change in monetary policy (e.g., as in Sims and Zha (2006)). The lag length $p$ in our model is set to 10.

Our measures of "household" and "business" credit are based on the Federal Reserve's weekly surveys of U.S. commercial banks. ${ }^{18}$ These data are different from the quarterly and annual series, based on a more comprehensive survey of lenders and categorized based on the borrower type (including "households and non-profits," "nonfinancial

\footnotetext{
17 This is a special case of the kind of normalization issue discussed by Hamilton, Waggoner and Zha (2007). 18 These are published in the H.8 "Assets and Liabilities of Commercial Banks in the United States" release.
} 


\begin{tabular}{ll}
\hline IP & Industrial production \\
P & Personal consumption expenditures price index \\
HHC & Sum of commercial bank real estate and consumer \\
& loans \\
BC & Commercial bank commercial \& industrial loans \\
M1 & M1 money supply \\
R & Federal funds rate \\
PCM & CRB/BLS spot (commodity) price index \\
TS & Term spread of 10 year over 3 month Treasuries \\
GZ & Gilchrist and Zakrajšek (2012) bond spread \\
ES & "TED spread" of 3-month Eurodollars over 3 month \\
& Treasuries \\
\hline
\end{tabular}

TABLE 1. Data series used in model estimation.

noncorporate business," and "nonfinancial corporate business"), used in some other research. ${ }^{19}$ Appendix 4.2 includes a more detailed discussion of the differences. Although our "household credit" series includes commercial real estate loans (which cannot be separately identified for the entire sample in the data) and our "business credit" data seems to have more high-frequency variation than the corresponding quarterly series, we believe these data capture the majority of the low-frequency behaviors that are critical for existing empirical evidence of their forecasting power. ${ }^{20}$

The inclusion of three credit spreads (of interest rates over short-term Treasuries) is meant to capture several possible dimensions of credit market stress: the term spread captures inflation expectations and uncertainty about future movements in fundamentals, the bond spread captures tightness in business financing, and the TED spread captures tightness in bank financing. The first was also expected to, along with the Federal Funds rate, M1, and commodity prices, provide a sharper identification of a monetary policy shock, as policy-generated rises in the short rate might be expected to have little effect on, or even lower, long rates, if the monetary tightening does succeed in lowering inflation.

$\overline{19}$ In particular, the cross-country database, assembled by the Bank of International Settlements uses these quarterly data.

${ }^{20}$ One practical complication is dealing with breaks in the credit series introduced by changes in accounting standards or major entrances to or exits from the commercial bank industry. Our specific calculations for eliminating these breaks, which are particularly large in the real estate credit series, are detailed in the Appendix 4.1. 


\begin{tabular}{llll}
\hline & Start & End & Description \\
\hline 1 & Jan 1973 & Sep 1979 & Oil crisis, stagflation, and Burns Federal Reserve \\
2 & Oct 1979 & Dec 1982 & Volcker disinflation \\
3 & Jan 1983 & Dec 1989 & Recovery from early 1980s recession \\
4 & Jan 1990 & Dec 2007 & Great Moderation and Greenspan Federal Reserve \\
5 & Jan 2008 & Dec 2010 & Great Recession \\
6 & Jan 2011 & Jun 2015 & Zero Lower Bound, Recovery from Great Recession \\
\hline
\end{tabular}

TABLE 2. Dates for variance regimes in full model specification.

\begin{tabular}{lc}
\hline \multicolumn{1}{c}{ Model } & MDD \\
\hline Gaussian, full data & 51768.38 \\
$t$, full data & 52490.13 \\
\hline
\end{tabular}

TABLE 3. Marginal data densities (marginal likelihoods) for two models of the full data sample (1973:1 to 2015:6). Differences between values are log Bayes factors, or log posterior odds with equal prior weights on each model.

\begin{tabular}{crrrrrrr}
\hline \multirow{2}{*}{ Shock } & Jan 1973 - & Oct 1979 - & Jan 1983 - & Jan 1990 - & Jan 2008 - & Jan 2011 - \\
& Sep 1979 & Dec 1982 & Dec 1989 & Dec 2007 & Dec 2010 & Jun 2015 \\
\hline IP & 1.255 & 1.336 & 0.767 & 0.807 & 1.306 & 0.610 \\
P & 0.856 & 0.946 & 0.902 & 0.875 & 1.190 & 1.119 \\
HH Credit & 0.676 & 0.533 & 0.413 & 1.700 & 1.675 & 0.934 \\
Firm Credit & 0.814 & 0.950 & 1.179 & 1.165 & 1.241 & 0.622 \\
M1 & 0.319 & 0.645 & 0.482 & 0.595 & 2.190 & 1.721 \\
Monetary Pol. & 1.031 & 4.147 & 0.585 & 0.109 & 0.087 & 0.004 \\
PCM & 1.275 & 0.832 & 0.760 & 0.722 & 1.729 & 0.575 \\
TS & 0.940 & 2.553 & 0.864 & 0.521 & 0.781 & 0.375 \\
GZ (Stress 1) & 0.764 & 0.484 & 0.533 & 0.717 & 2.823 & 0.632 \\
ES (Stress 2) & 1.565 & 1.917 & 0.543 & 0.286 & 1.707 & 0.009 \\
\hline
\end{tabular}

TABLE 4. Posterior median relative variances for each of ten shocks in six periods, from a model with $t$-distributed innovations.

We separate the full sample into six variance regimes described in Table 2. From the standpoint of estimation efficiency, we expect the separate treatment of the Volcker disinflation and Great Recession to discourage overfitting of high monetary policy and financial stress variations respectively by allowing the model to "down-weight" these periods' residuals.

Table 3 displays estimates of the marginal data densities of the model with Gaussian distributed shocks and the model with Student's $t$ distributed shocks. These are reported in a $\log$ points scale, so a difference of over 100 is extremely strong evidence (i.e., more 
than an $e^{100}$ odds ratio) in favor of the better model. The $t$ model clearly fits much better than the model with Gaussian errors. ${ }^{21}$

II.1. The structural impulse responses. Figures 1 to 4 , in four 5 by 5 "blocks," show the impulse response over five years of all 10 variables to the model's orthogonal structural shocks, scaled to draws from a unit-scale $t$ distribution with 5.7 degrees of freedom. Since the diagonal of $\Lambda_{i}$ is normalized to sum to one across ruegimes, these responses are a kind of average across regimes.

In principle structural VAR shocks need not be associated with single variables in the system. However in these monthly data, the reduced form shocks, which are variableby-variable innovations, show only modest cross-variable correlations. Since our prior mildly favors $A_{0}$ matrices with positive entries on the diagonal, the structural estimates still have shocks that are not far from being innovations in a single variable. Accordingly, with one exception, in the discussion and plots below we name shocks by the variable they are most strongly associated with. The exception is the "interest rate shock", which has large contemporaneous effects not just on the short interest rate, but also on the term spread and the interbank (ES) spread.

We name this shock the "Monetary Policy" shock. Despite the model's lack of any identifying zero restrictions on coefficients, this shock emerges as having the characteristics usually associated with monetary policy shocks. It is the only one that has an immediate positive $\mathrm{R}$ response, a delayed negative IP response, a negative (though ill-determined) long run $\mathrm{P}$ response, negative responses of $\mathrm{M} 1$ and the two credit aggregates, and a negative response of the term spread (as would be expected if the shock raises current interest rates and lowers expectations of future inflation).

The two spread shocks are the most important sources of variation in the GZ spread and ES spreads. The two spreads do not tend to move together in response to these shocks, and the two have different patterns of effects on other variables. Both depress IP. Both depress P, though in the case of the ES shock this effect is statistically weak. The shock we label GZ has a strong delayed effect in depressing BC, but modest and indeterminate-signed effect on HHC, while the shock we label ES, which immediately impacts ES, strongly depresses HHC with ill-determined effect on BC. The ES shock produces a quick and strong expansionary movement in $\mathrm{R}$, while the GZ shock is followed by a smoother, more delayed response of $\mathrm{R}$. These patterns seem to fit an interpretation that distinguishes a banking credit shock (ES) from a non-bank financial disturbance (GZ). All the effects of these shocks on other variables are delayed, while their effects on the spread

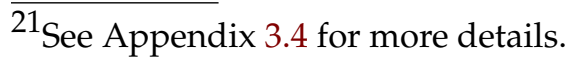


variables are immediate. This fits an interpretation that they reflect disturbances originating in financial markets, with monetary policy trying to partially offset their effects.

The shocks we label HH and Firm Credit start with an impulse to household credit and to business credit (net of inflation), respectively. They lead to persistent, but marginally statistically significant, long-term declines in output. They qualitatively match the "excessive credit growth" story demonstrated empirically by Mian, Sufi and Verner (2017), Schularick and Taylor (2012), and others, but might seem small in the light of that earlier literature. We discuss the interpretation of these shocks and their comparison to earlier literature in more detail in section II.5.

The PCM shock accounts for both the main component of variation in PCM and a substantial component of the variation in P. Its immediate effect is to increase commodity prices. The effect on commodity prices is persistent. With some delay, P (the PCE deflator) moves up. BC, but not HHC moves up slightly. This looks like a commodity supply shock. ${ }^{22}$

These core impulse response results seem largely robust to the alternative error specifications. We provide full impulse response plots for versions of the model with Gaussian errors in Appendix 6.1.

The picture is also very similar if we estimate with data only up to December 2007. Full impulse responses from this sample period are plotted in Appendix 6.2. In particular, the identification of monetary policy and spread effects is very stable. There is weak (within $68 \%$, but not $90 \%$ bands) evidence of an output response to household and business credit expansion shocks. These effects are of comparable magnitude to the estimated credit effects in the model estimated on the full dataset.

II.2. Structural shock volatility. Our results suggest that the variances of these shocks change substantially among periods. Table 4 reports the variances of each of the ten structural shocks in the posterior mode $t$-errors model, over the full sample. $90 \%$ probability bands for these relative variances are quite tight, mostly within 0.8 to 1.2 times the posterior median estimate. In general, there is strong evidence of time-varying variance. Several of the shocks spike in variance during the financial crisis (period 5). The sixth shock, which we identify as a monetary policy shock, has a considerably inflated variance in the Volcker disinflation period and almost zero variance in the most recent period (near the zero lower bound).

\footnotetext{
${ }^{22}$ The Gaussian-errors version of the model shows a modest, marginally statistically significant, negative IP response to this shock. See the appendix Figure 7.
} 


\begin{tabular}{rcr|rrr}
\hline Month & $\epsilon_{i t}$ & $\mathrm{~d} y_{i, t}$ & \multicolumn{1}{|c}{ Month } & \multicolumn{3}{c}{$\epsilon_{i t}$} & $\mathrm{~d} y_{i, t}$ \\
\hline \multicolumn{3}{c|}{ IP } & & \multicolumn{3}{|c}{ Monetary Policy } \\
\hline $9 / 2008$ & -9.875 & -0.043 & $5 / 1980$ & -22.627 & -0.067 \\
$12 / 1974$ & -6.259 & -0.027 & $3 / 1980$ & 10.409 & 0.031 \\
$1 / 1983$ & 5.160 & 0.022 & $2 / 1981$ & -10.135 & -0.030 \\
$4 / 1980$ & -5.015 & -0.022 & $5 / 1981$ & 9.312 & 0.028 \\
& $\mathrm{P}$ & & \multicolumn{4}{|c}{$\mathrm{PCM}$} \\
\hline $9 / 2005$ & 5.492 & 0.007 & $8 / 1976$ & -4.222 & -0.066 \\
$1 / 1990$ & 3.820 & 0.005 & $7 / 1975$ & 4.096 & 0.064 \\
$11 / 2005$ & -3.748 & -0.005 & $7 / 1974$ & 3.901 & 0.060 \\
$11 / 2008$ & -3.453 & -0.005 & $2 / 1974$ & 3.777 & 0.059 \\
& HHC & & & $\mathrm{TS}$ & \\
\hline $12 / 1999$ & 7.068 & 0.015 & $8 / 1974$ & -7.157 & -0.014 \\
$9 / 2008$ & 5.922 & 0.012 & $6 / 1981$ & 6.261 & 0.012 \\
$10 / 2003$ & -5.861 & -0.012 & $11 / 2008$ & 5.871 & 0.011 \\
$10 / 2002$ & 4.933 & 0.010 & $4 / 1980$ & 4.411 & 0.008 \\
& BC & & & $\mathrm{GZ}$ & \\
\hline $10 / 2008$ & 5.247 & 0.019 & $10 / 2008$ & 18.275 & 0.023 \\
$12 / 1986$ & 5.216 & 0.019 & $1 / 2009$ & -7.844 & -0.010 \\
$9 / 2007$ & 4.454 & 0.016 & $9 / 2008$ & 7.183 & 0.009 \\
$11 / 1999$ & 4.283 & 0.016 & $7 / 2002$ & 6.771 & 0.009 \\
& M1 & & & ES & \\
\hline $10 / 2001$ & -9.766 & -0.047 & $10 / 2008$ & 10.840 & 0.019 \\
$8 / 2011$ & 8.507 & 0.041 & $7 / 1974$ & 8.950 & 0.016 \\
$9 / 2001$ & 8.431 & 0.041 & $9 / 2008$ & 7.739 & 0.014 \\
$9 / 2008$ & 6.773 & 0.033 & $12 / 1973$ & 7.148 & 0.013 \\
\hline
\end{tabular}

TABLE 5. Four largest residuals for each shock in the main model. Point estimates are posterior medians.

Table 5 lists the 4 largest posterior median shocks for each equation. These are in standard deviation units and not scaled by the corresponding $\lambda$ values. They thus show the biggest shocks, not the biggest "surprises" for the model.

The biggest of these, in the monetary policy shock, reflects a sudden easing of monetary policy in May 1980, during the recession of that year. The Federal Funds rate fell from 18 per cent to 11 percent in that month, but soon started rising again. There were also large values for this shock in March 1980, February 1981, and May 1981. These were all during the period of Volcker unborrowed reserve targeting, which has a high value of $\lambda$ for this shock. That is, though large, these shocks occur in a period the model has identified as a high-variance period.

The second and third largest shocks were in the two financial stress indicators, at the time of the Lehman collapse in October 2008. The IP shock, which accounts for much of 
the variance in output and looks like a "demand" shock, was sharply negative in September 2008, reflecting the large decline in industrial production as the crisis took hold. The September 2001 attack on the US shows up in the M1 shock, which looks like an accommodated money demand shock. The shock is sharply negative in October 2001 as the Fed withdrew its temporary liquidity accommodation. It was nearly as large and positive in the previous month. The PCM shock, takes on large values in 1974-5.

The largest of these shocks all correspond to events that were recognizably unusual as they occurred. But they tend to come from periods with large values of $\lambda_{i t}$, so they are not necessarily the biggest surprises. Looking at the largest surprises - the $\epsilon_{i t} / \sqrt{\lambda_{i t}}$ values - is useful because it is these residuals that have the biggest impact on model fit. Also the size and distribution across variables of these large surprises casts some doubt on our assumption of i.i.d. $t$-distributed scaled shocks. We discuss the surprises in Appendix 5.

The remainder of this section reviews the model dynamics of key shocks in greater detail.

II.3. The credit channel of monetary policy. The model provides substantial evidence that the effect of monetary policy changes in the policy rate is amplified by corresponding movements in interest rate spreads. In particular, the 3-month Eurodollar spread over Treasuries increases about 1 basis point per 4 in the Federal Funds rate and decays over a similar horizon. This response accounts for about as much of the variance in the ES spread as does the response to the ES shock itself. There is relatively little evidence, in contrast, that the bond premium moves in the short run (i.e., within the first 6 months) and no evidence that the effect persists longer. The general finding of financial amplification of monetary policy shocks is consistent with the empirical results of Gertler and Karadi (2015) and a variety of theoretical models which suggest that risk premia should move in response to monetary policy (e.g., Drechsler, Savov and Schnabl (2016) and Brunnermeier and Sannikov (2016)). Our empirical result is focused, however, on inter-bank credit conditions separate from firm-level credit conditions. This is concurrent with our broader empirical point that the information content of credit spreads in the multi-variate model is multi-dimensional - movements in different spreads forecast different macro-financial dynamics and, potentially, relate to different economic mechanisms.

II.4. Spread spikes and early warning. Three independent shocks can be identified by sharp increases in spreads at $t=0$, but only the ES and GZ shocks (the responses to which are plotted in Figure 7) have significant output effects. The output effect is larger and more significant for the bond spread (GZ) shock, associated with an initial surge in the corporate bond spread and a long-term contraction in business credit. The ES shock, 
in contrast, begins with a shock to the inter-bank lending rate of comparable magnitude to the impulse following a monetary policy shock, a significant long-term contraction in household credit, and a modestly significant short-term output contraction. It also shows a quicker and stronger $\mathrm{R}$ decline following the shock, implying a stronger monetary loosening, in response to the generated output decline. The fitting of two independent "stress shocks," with quantitatively different macro effects, suggests the importance of a multidimensional approach to measuring financial stress.

In the historical record, inter-bank shocks have almost as high a variance in the early sample (1973 to 1982) as they do in the financial crisis (Table 4). With post-2009 interbank rates very close to short rates at zero, this channel almost completely shuts down in the final variance period. The corporate bond spread shock, in contrast, is by some margin highest variance during the 2008 financial crisis.

Taken together, the impulse response and the estimated variances suggest that the macro importance of spread shocks-closely related to the forecasting value of the spread variables-is concentrated during certain high variance episodes and largest at short horizons. Interest rates react to the corporate and inter-bank spread shocks by falling, as would be expected from a monetary policy easing. Because the response of IP to monetary policy is slower and more persistent than its response to these spread shocks, it is not clear that monetary policy could do more to mitigate the output decline without creating more instability.

We will return to discussion of the contribution of financial variables to forecasting in section IV, where we show results of pseudo-out-of-sample forecasting.

II.5. Credit growth and recessions. Our main model offers some support, within $68 \%$ error bands, of the hypothesis that excessive growth in household credit can forecast negative long-term real output growth (Figure 8). The shape of our estimated output responses to the two credit shocks HHC and BC, with a short-term output boost and long-term contraction, are similar to those found in a small-system (household credit to GDP, business credit to GDP, and real GDP) VAR by Mian, Sufi and Verner (2017). In our model the response to the HHC shock, which raises HHC by about 1 per cent over five years, is a small increase in IP, on the order of 0.1 per cent, that lasts less than a year, followed by a decline that reaches $-0.1 \%$ after five years. Mian, Sufi and Verner (2017) find a larger initial rise of about $0.2 \%$, over two years, but also a subsequent decline that reaches about $-0.1 \%$ after five years. Our estimates show a five-year negative response to the $\mathrm{BC}$ shock that is similar in size and statistical significance to the estimated response to HHC, though without the initial positive response. This also is consistent with the Mian, Sufi 
and Verner (2017) business credit estimated responses. All these results have fairly wide error bands, so there is no statistically sharp difference between the models. This might not have been expected, since these other authors use an international panel of annual data and a smaller model, while we use monthly US data and a big model.

However, our model implies that the decline in output growth following this shock can be entirely accounted for by the rise in interest rates it elicits. The response of the system to the credit shocks, combined with a sequence of monetary policy shock values that keep the interest rate constant, eliminates the decline in output (Figure 5). Of course this does not imply that the monetary contraction following a credit aggregate shock is a mistake. The credit shocks are followed by an increase in inflation; without the monetary policy reaction, the inflation would be larger and more persistent.

Though the credit shocks are followed by future declines in output growth, they are not followed by substantial movements in the spread variables GZ and ES. The spread shocks, on the other hand, are followed by substantial declines in credit aggregates. Our interpretation is that the credit expansions generated by the credit shocks are followed with a delay by slow growth due to monetary tightening, not financial market distress.

A different way to assess the economic significance of credit shocks in our model is to calculate the share of forecast errors that are explained by each shock (Figure 9). ${ }^{23}$ The importance of third and fourth shocks for explaining credit variation starts very high (as it has by far the largest contemporaneous impact on credit) but decays over time. Over five years, these shocks explain $20 \%$ and $24 \%$ respectively of forecast error variance household and business credit. The remainder of credit variation over these horizons is explained by the other shocks in the model, which are all associated with credit and output moving in the same direction, or with output scarcely moving at all. Over five years, the same "bad credit shocks" explain $1.4 \%$ and $1.6 \%$, respectively, of forecast error variance in industrial production.

In the period 1990-2007, when the variance of the credit shocks is relatively high and the variance of others relatively low, the two credit shocks explain a higher fraction of five-year-ahead variance in the two aggregates $(49.5 \%$ for household credit and shock 3 , and $37.6 \%$ for business credit and shock 4 ) and a higher, though still small, percentage of output variation at the same horizon ( $4.1 \%$ and $3.2 \%$ respectively).

\footnotetext{
${ }^{23}$ These are the squared impulse responses scaled to sum to one for each response variable in each period. Precisely, the variance decomposition of variable $i$ is, for each $j$ and each time horizon $s$, the proportion of $s$-step ahead forecast error variance in variabale $i$ attributable to shock $j$.
} 


\section{Accounting for the Predictive Power of CRedit in Small Models}

There is a recent literature that claims to show that credit expansion predicts negative growth and/or financial crises. Our model does not suggest that credit expansion predicts financial crises and shows the negative association of credit growth with future output growth as a small component of the overall relation between credit and output. But our model does not contradict the earlier results with smaller models. It is compatible with them.

As we have already observed, the responses to shocks three and four in our model lie within error bands of the responses to credit-to-gdp-ratio shocks in Mian, Sufi and Verner (2017). Those authors also estimate single-equation regressions of growth in real output over the next three years on growth in credit in the past three years, finding that a one-standard-deviation increase in 3-year household credit growth predicts a $2.1 \%$ lower growth rate of output in the subsequent three years. they find no such effect with business credit. When we replicate those regressions using our data, we find that a one standard deviation increase in the three-year growth rate of $\mathrm{BC}$ predicts a 1.7 percentage point decline in the subsequent three year growth rate of output. We find no such predicted effect from increased household credit growth. ${ }^{24}$

So our data show a similarly strong negative effect of three-year credit expansion on output growth, but shifts the strong effect estimated from a 3-variable reduced form VAR from household to business credit. Even though our data are in this way consistent with the results of Mian, Sufi and Verner, the large monthly model estimates might have damped down this regularity in the data, so that the estimated large model implies these small model reduced form results are rare outliers.

To check this, we can replicate those regressions on data simulated from our model, ${ }^{25}$ and we find that with substantial probability our results from simulated data are of similar size and sign to those found in the actual data. The results are in Table 6. To form the table we used three-year forward differences of the log of real output (IP) as the dependent variable, three-year backward differences in real credit (credit over price level) over output as the main independent variable, and lags of first differences of log output as an extra independent variable. In equation form, with $y_{t}$ denoting $\log \mathrm{IP}, h c_{t}$ the ratio of household credit deflated by PCEPI to IP, and $b c_{t}$ the ratio of business credit deflated

\footnotetext{
${ }^{24}$ When we substitute flow of funds data on business credit and household credit for the our HHC and BC, the effects of HHC and BC increases by one standard deviation are both negative, with HHC producing a 1.6 percentage point decline and business credit a 0.6 percentage point decline.

${ }^{25}$ We generated simulated annual data by simulating our monthly model, starting from actual data initial conditions, and converting the simulated log data to levels. Then we applied the log or ratio transformations needed to match the earlier estimates, as described below.
} 
Proportion of negative effects

\begin{tabular}{crr} 
& Household Credit & Business Credit \\
\cline { 2 - 3 } without lagged IP & 0.55 & 0.56 \\
with lagged IP & 0.53 & 0.57 \\
\hline
\end{tabular}

Proportion of economically significant negative effects

\begin{tabular}{crr} 
& Household Credit & Business Credit \\
\cline { 2 - 3 } without lagged IP & 0.29 & 0.31 \\
with lagged IP & 0.30 & 0.33
\end{tabular}

TABLE 6. Probability, in simulated draws of coefficients and data from the posterior distribution under the $t$-distributed errors model, of a negative or "economically significant" effect of previous 3-year credit growth on subsequent three-year output growth. An economically significant effect is one that makes a one-standard-deviation change in credit growth produce a 2 percentage point or larger change in output growth rate.

by PCEPI to IP,

$$
y_{t+3}-y_{t}=\alpha+\beta_{h}\left(h c_{t}-h c_{t-3}\right)+\beta_{b}\left(b c_{t}-b c_{t-3}\right)+\sum_{i=1}^{k} \gamma_{i}\left(y_{t-i+1}-y_{t-i}\right) .
$$

Table 6 reports probabilities for $\beta_{h}$ and $\beta_{b}$. The results "with lagged IP" set $k=3$; otherwise we set all $\gamma_{i} \equiv 0$.

In these simulated draws from our model's data distribution we find the probability of credit growth coefficients smaller than 0 to be over .5 and negative enough that a one standard deviation increase in credit growth reduces output growth by 2 percentage points or more with probability about .3. Note that in the simulated data, it is about equally likely that the $\mathrm{BC}$ or the HHC predictive effect will be large and negative. This suggests that, according to our model, this one-equation model could suggest strong predictive power when the fully specified structural model attributes a limited causal role to credit innovations.

\section{CREDit CONDITIONS AND FORECASTING}

So far we have demonstrated that credit variables have an interesting interpretation within the model. But are they practically helpful to include, and could this have been realized before the 2008 financial crisis? We find that information in spreads can be useful for short-term forecasting at the onset of a crisis. The model with spreads does not, however, provide much advanced warning of a crisis or any clear advantage in "normal" times outside of recessions. 
IV.1. Forecasting in the recent financial crisis. We first focus on the 2007-08 financial crisis and its immediate aftermath. At each month between January 2007 and December 2010, we estimate (posterior modes of) models with and without credit variables using data only up to that point and then calculate 12-month forecasts. This "pseudo-out-ofsample forecasting" exercise offers a dimension in which to compare models with different data lists and gives a sense of how much changing the emphasized data in macro models would have helped in real time.We focus on the Gaussian errors specification, despite its fitting more poorly than the $t$ model, because it seems to capture the main model dynamics and is much easier to do recursive computations with.

Figures 10, 11, and 12 plot posterior mode forecasts from our (Gaussian error) model with 10 variables, a version without the credit aggregates, and a version without the spreads, respectively, at 3-month intervals from January 2007 to October 2010. The model without spreads (Figure 12) never fully "accepts" the crisis, predicting a return to near pre-crisis growth rates at each point during the deepest contraction. The models with spreads (with or without credit aggregates) give slightly less optimistic forecasts in early 2008, at which point the bond and inter-bank spreads have elevated slightly over mid2000 s levels. But the most obvious improvement is the models' ability to grasp the severity of the crisis during the deepest fall from mid 2008 to mid 2009. This observation is consistent with the previous section's analysis of impulse responses, which suggested that the model could identify spread shocks which have macro effects within the first few months. The spreads provide little advance warning of severe recession but do enhance recognition of the severe recession, and its likely persistence, once it is underway.

The addition of credit aggregates seems considerably less important. With spread variables alone, with them and also credit aggregates, the model is quicker to recognize a persistent downturn. While forecasts of IP are little affected by excluding credit aggregates, the model without them consistently predicts that interest rates will start reverting to positive values from the zero lower bound, though this seems to have limited effects on forecasted output or consumer prices.

IV.2. Forecasting Power in the Entire Sample. We generalize the exercise of the previous section by calculating forecasts with versions of the main model, the no spreads model, and the no credit model estimated up to each month from October 1979 to June $2015 .{ }^{26}$

26 The truncation at the beginning of the sample comes from the requirement of having two variance regimes to identify the parameters. Unfortunately, this cuts out some interesting macreconomic turbulence in the 1970s.

Additionally, for the period October 1979 to December 1982, we use models with six lags because of the smaller availability of data. 
We focus on root mean squared error (RMSE) for forecasts of all variables common to the models.

Figures 13 and 14 display the evolution of these RMSE for the base model with all variables (blue), a model without spreads (red), and a model without credit aggregates (green). As suspected from the previous section, the models with spreads does a significantly better job predicting output just before and during the 2007-2009 financial crisis and recession. The model's internal projections for the Federal Funds rate are quite a bit better at the zero lower bound, though this comes at the cost of one set of very poor forecasts right around the major rate reduction in late 2008. Any advantages in forecasting the price level and credit aggregates in the crisis are less obvious.

Outside the recent financial crisis, and potentially the early 1980s and early 2000s recessions, the no spread model seems to perform just as well if not better. We might suspect that a formal or informal comparison of models before 2008 would not clearly support the inclusion of the financial variables, even if the estimated dynamics from such a model look like they have "economically interesting" transmissions from spreads to macro variables. Alternatively, the model with spreads might only be better for forecasting when economic conditions worsen. ${ }^{27}$

The model without credit aggregates, but with credit spreads, seems to match the full model quite closely throughout the sample. One exception seems to be the early part of the 1981-1982 recession and the subsequent uptick in growth around 1984. In several periods, including post-recession growth in the early 90s and 2010s, the no credit model is significantly better at predicting output. In general there is no clear pattern of the model with credit aggregates, after including spreads, doing a better job of forecasting the timing or severity of U.S. recessions.

\section{ROBUSTNESS}

We have tried a number of variants on our model to check robustness of our results. These are described in detail in the appendix. Our checks include varying the assumption on error distributions (Appendix 6.1), estimating models with triangular Cholesky identification (Appendix 6.3), looking for nonlinearity via various nonlinear transformations of the data (Appendix 6.5), and estimating quarterly models (Appendix 8). Details of these and other experiments are in the Appendix. Of course the model we present as our main model is itself the result of experiments like this, where we have adopted

${ }^{27}$ These nuances could be captured formally by taking posterior forecasts averaged across an "ensemble" of models, the weights on which change over time (for instance, with some approximation of posterior odds). To capture them within the model might require some more complex (and possibly endogenous) modeling of regime switching. 
specifications when we found them fitting better. As a result, the robustness checks in the Appendix do not cast doubt on our main specification.

\section{CONCLUSION}

Credit conditions, monetary policy, and real activity interact dynamically through multiple channels. To study these interactions, we construct and estimate structural multipleequation models that are identified without strong a priori assumptions. Our analysis distinguishes impulses and feedbacks that focused study of individual channels might miss.

Our main model includes ten independent shocks that are identified by substantially changing volatilities across exogenously specified regimes. The data strongly favor additional corrections for fat tails in the distributions of the structural innovations, though the main qualitative conclusions are the same without them. Further refining (and possibly endogenizing) a model specification for volatility remains a task for future research, but addressing the issue in some way greatly improves model fit and affects implied dynamics.

Monetary policy is identified without any timing restrictions and seems to be amplified through inter-bank credit spreads. Two other model shocks look like "stress shocks" which originate in the financial sector and propagate to the real economy after several months of delay. The distinction between these shocks, which start with impulses to corporate bond spreads and interbank rate spreads respectively, is potentially very important for emerging research on the role of lending frictions and risk premia in the macroeconomy. A related takeaway for forecasters is that one-dimensional metrics of financial conditions may be insufficient for capturing risks for the real economy.

While these credit spread shocks do have strong real effects, they do not provide more than a few months of "advance warning" of an output contraction. In recursive-outof-sample forecasts around the 2008 financial crisis, including additional credit spread variables only improves forecasts in a narrow window at the beginning of the downturn. Across the entire data sample, there is no clear evidence that including credit variables improves forecasting performance.

Credit aggregates in this model mainly move "passively" in the same direction as output. Two shocks generate opposite movements in household (real estate plus consumer) or business credit and output, but in all periods the magnitude of these effects is relatively small. They are accompanied by rising interest rates, and if monetary policy offsets that rise, the effect of the credit shocks on output would disappear. To the extent that this 
effect is quantitatively important, a multivariate model is necessary to properly separate it from other effects. 


\section{REFERENCES}

Bernanke, Ben S., Mark Gertler, and Simon Gilchrist. 1999. "The financial accelerator in a quantitative business cycle framework." In Handbook of Macroeconomics. Vol. 1 of Handbook of Macroeconomics, , ed. J. B. Taylor and M. Woodford, Chapter 21, 1341-1393. Elsevier.

Borio, Claudio. 2012. "The financial cycle and macroeconomics: What have we learnt?" Bankf for International Settlements Workin paper 395.

Brunnermeier, Markus K., and Yuliy Sannikov. 2016. “The I Theory of Money.” Princeton University Working Paper.

Caldara, Dario, and Edward Herbst. 2016. "Monetary Policy, Real Activity, and Credit Spreads: Evidence from Bayesian Proxy SVARs." Board of Governors of the Federal Reserve System Finance and Economics Discussion Series Paper 2016-049.

Chib, Siddhartha, and Srikanth Ramamurthy. 2014. "DSGE Models with Student-t Errors." Econometric Reviews, 33(1-4): 152-171.

Chiu, Ching-Wai, Haroon Mumtaz, and Gabor Pinter. 2015. "Forecasting with VAR models: fat tails and stochastic volatility." Bank of England Bank of England working papers 528.

Christiano, Lawrence J., Roberto Motto, and Massimo Rostagno. 2014. "Risk Shocks." American Economic Review, 104(1): 27-65.

Cúrdia, Vasco, Marco Del Negro, and Daniel L. Greenwald. 2014. "Rare Shocks, Great Recessions." Journal of Applied Econometrics, 29(7): 1031-1052.

Del Negro, Marco, and Frank Schorfheide. 2013. "DSGE Model-Based Forecasting." Handbook of Economic Forecasting, , ed. Graham Elliott and Allan Timmermann Vol. 2, Part A of Handbook of Economic Forecasting, Chapter 2, 57 - 140. Elsevier.

Drechsler, Itamar, Alexi Savov, and Philipp Schnabl. 2016. "A Model of Monetary Policy and Risk Premia." Journal of Finance, NA((forthcoming)): NA.

Drehmann, Mathias, and Mikael Juselius. 2014. "Evaluating early warning indicators of banking crises: Satisfying policy requirements." International Journal of Forecasting, 30(3): 759-780.

Gelman, Andrew, John B. Carlin, Hal S. Stern, David B. Dunson, Aki Vehtari, and Donald B. Rubin. 2014. Bayesian Data Analysis. CRC Press.

Gertler, Mark, and Peter Karadi. 2015. “Monetary Policy Surprises, Credit Costs, and Economic Activity." American Economic Journal: Macroeconomics, 7(1): 44-76.

Gilchrist, Simon, and Egon Zakrajšek. 2012. "Credit Spreads and Business Cycle Fluctuations." American Economic Review, 102(4): 1692-1720. 
Gilchrist, Simon, Vladimir Yankov, and Egon Zakrajšek. 2009. "Credit market shocks and economic fluctuations: Evidence from corporate bond and stock markets." Journal of Monetary Economics, 56(4): 471 - 493.

Goldsmith, Raymond. 1969. Financial Structure and Development. Yale University Press.

Hamilton, James D., Daniel F. Waggoner, and Tao Zha. 2007. "Normalization in Econometrics." Econometric Reviews, 26(2-4): 221-252.

Jordà, Òscar, Moritz Schularick, and Alan M. Taylor. 2014. “The Great Mortgaging: Housing Finance, Crises, and Business Cycles." National Bureau of Economic Research Working Paper 20501.

Jordà, Òscar, Moritz Schularick, and Alan M. Taylor. 2015. "Betting the house." Journal of International Economics, 96, Supplement 1: S2 - S18. 37th Annual NBER International Seminar on Macroeconomics.

Krishnamurthy, Arvind, and Tyler Muir. 2016. "How Credit Cycles across a Financial Crisis." Stanford GSB Working Paper.

Lanne, Markku, and Helmut Lütkepoh1. 2010. "Structural Vector Autoregressions With Nonnormal Residuals." Journal of Business \& Economic Statistics, 28(1): 159-168.

Lanne, Markku, Helmut Lütkepohl, and Katarzyna Maciejowska. 2010. "Structural vector autoregressions with Markov switching." Journal of Economic Dynamics and Control, 34(2): $121-131$.

Lopez-Salido, David, Jeremy C. Stein, and Egon Zakrajsek. 2015. "Credit-Market Sentiment and the Business Cycle." Board of Governors of the Federal Reserve System Working Paper.

McKinnon, Ronald. 1973. Money and Capital in Economic Development. Washington, D.C.:Brookings Institution.

Mian, Atif R., Amir Sufi, and Emil Verner. 2017. "Household Debt and Business Cycles Worldwide." Quarterly Journal of Economics, Forthcoming.

Rajan, Raghuram G., and Luigi Zingales. 1998. "Financial Dependence and Growth." American Economic Review, 88(3): 559-586.

Rigobon, Roberto. 2003. "Identification through Heteroskedasticity." The Review of Economics and Statistics, 85(4): 777-792.

Schularick, Moritz, and Alan M. Taylor. 2012. "Credit Booms Gone Bust: Monetary Policy, Leverage Cycles, and Financial Crises, 1870-2008." American Economic Review, 102(2): 1029-61.

Shaw, Edward Stone. 1973. Financial Deepning in Economic Development. New York:Oxford Univ. Press.

Sims, Christopher A., and Tao Zha. 1996. "Bayesian methods for dynamic multivariate 
models." Federal Reserve Bank of Atlanta FRB Atlanta Working Paper 96-13.

Sims, Christopher A., and Tao Zha. 1999. "Error Bands for Impulse Responses." Econometrica, 67(5): 1113-1155.

Sims, Christopher A., and Tao Zha. 2006. "Were There Regime Switches in U.S. Monetary Policy?" American Economic Review, 96(1): 54-81.

Smets, Frank, and Rafael Wouters. 2007. "Shocks and Frictions in US Business Cycles: A Bayesian DSGE Approach." American Economic Review, 97(3): 586-606.

World Bank. 2012. Global Financial Development Report 2013: Rethinking the Role of the State in Finance. Washington, DC:World Bank.

DePartment of ECONOMICS, PRINCETON UNIVERSiTy

E-mail address: markuseprincet on.edu

Department of FinANCE AND ECONOMics, Rutgers Business SCHOOL

E-mail address: dpalia@business.rutgers.edu

DEPARTMENT OF ECONOMICS, MIT

E-mail address: ksastry@mit.edu

DePartment of ECONOMICS, Princeton University

E-mail address: sims@princeton.edu 

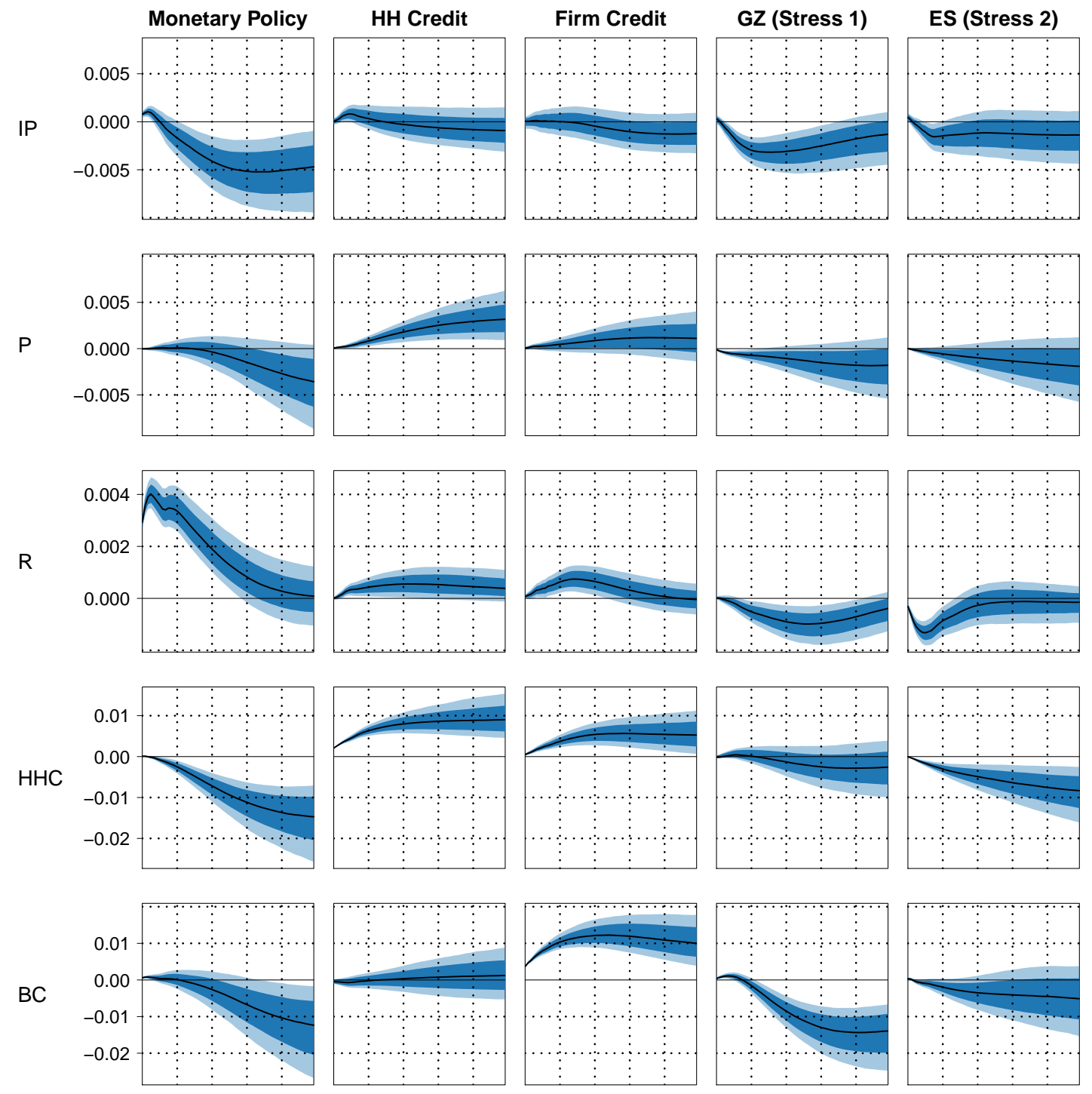

FIGURE 1. (1/4) Impulse responses to the ten orthogonal structural shocks in the model with $t$ distributed errors over 60 months, with $68 \%$ (dark blue) and $90 \%$ (light blue) posterior uncertainty regions. Scaled to an "average" period with unit scale. 

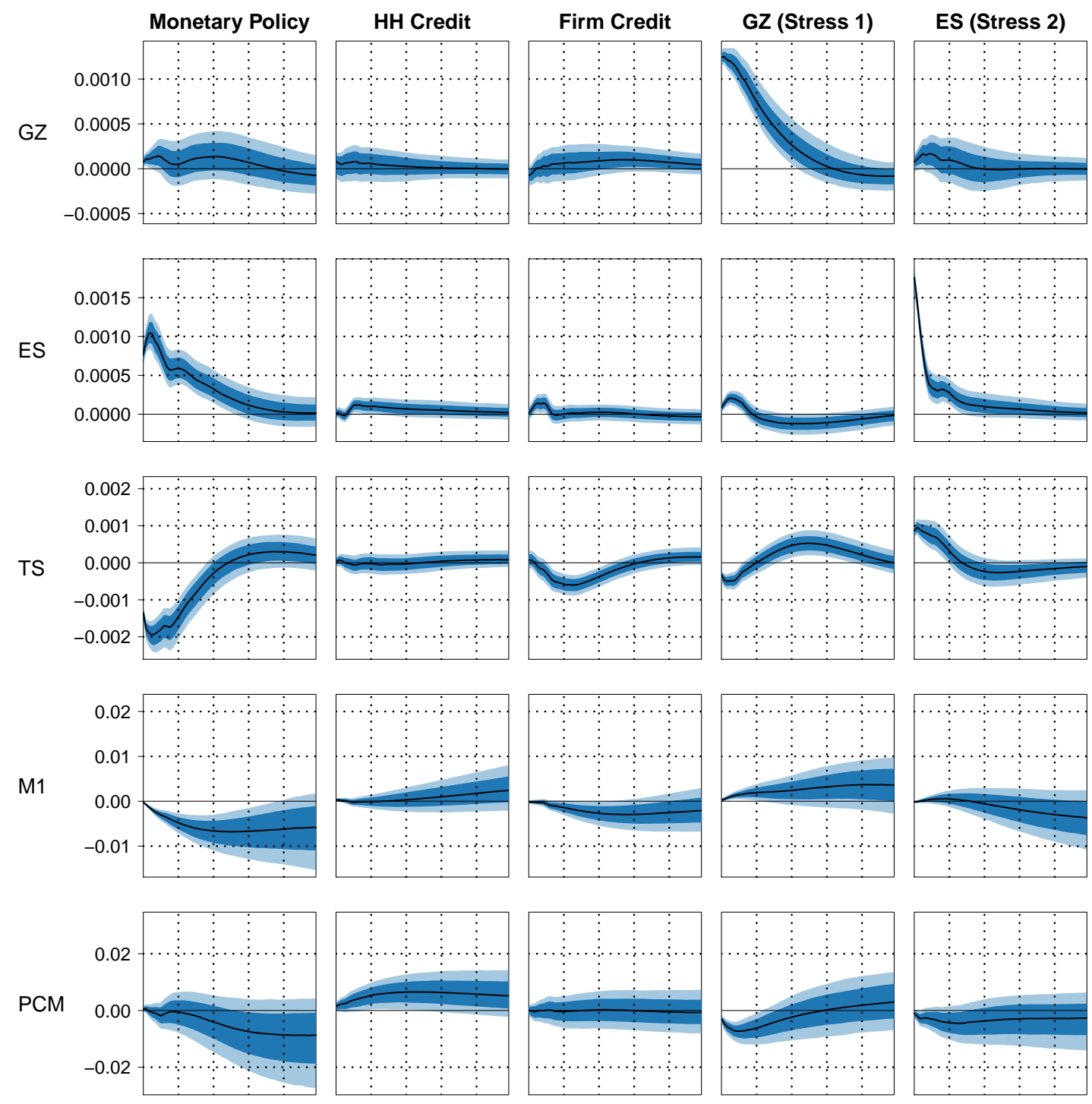

FIGURE 2. (2/4) Impulse responses to the ten orthogonal structural shocks in the model with $t$ distributed errors over 60 months, with $68 \%$ (dark blue) and $90 \%$ (light blue) posterior uncertainty regions. Scaled to an "average" period with unit scale. 

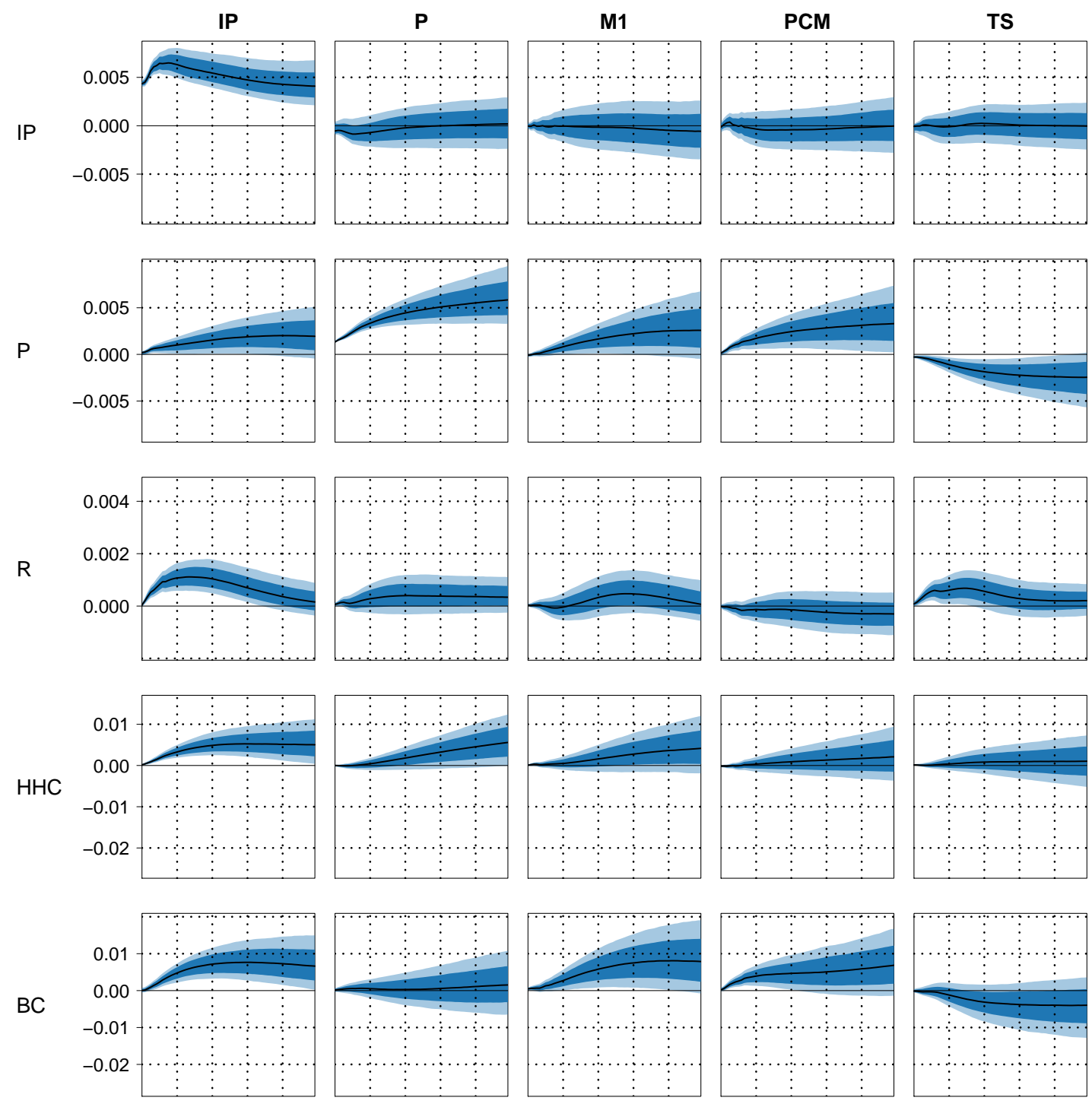

FIGURE 3. (3/4) Impulse responses to the ten orthogonal structural shocks in the model with $t$ distributed errors over 60 months, with $68 \%$ (dark blue) and $90 \%$ (light blue) posterior uncertainty regions. Scaled to an "average" period with unit scale. 

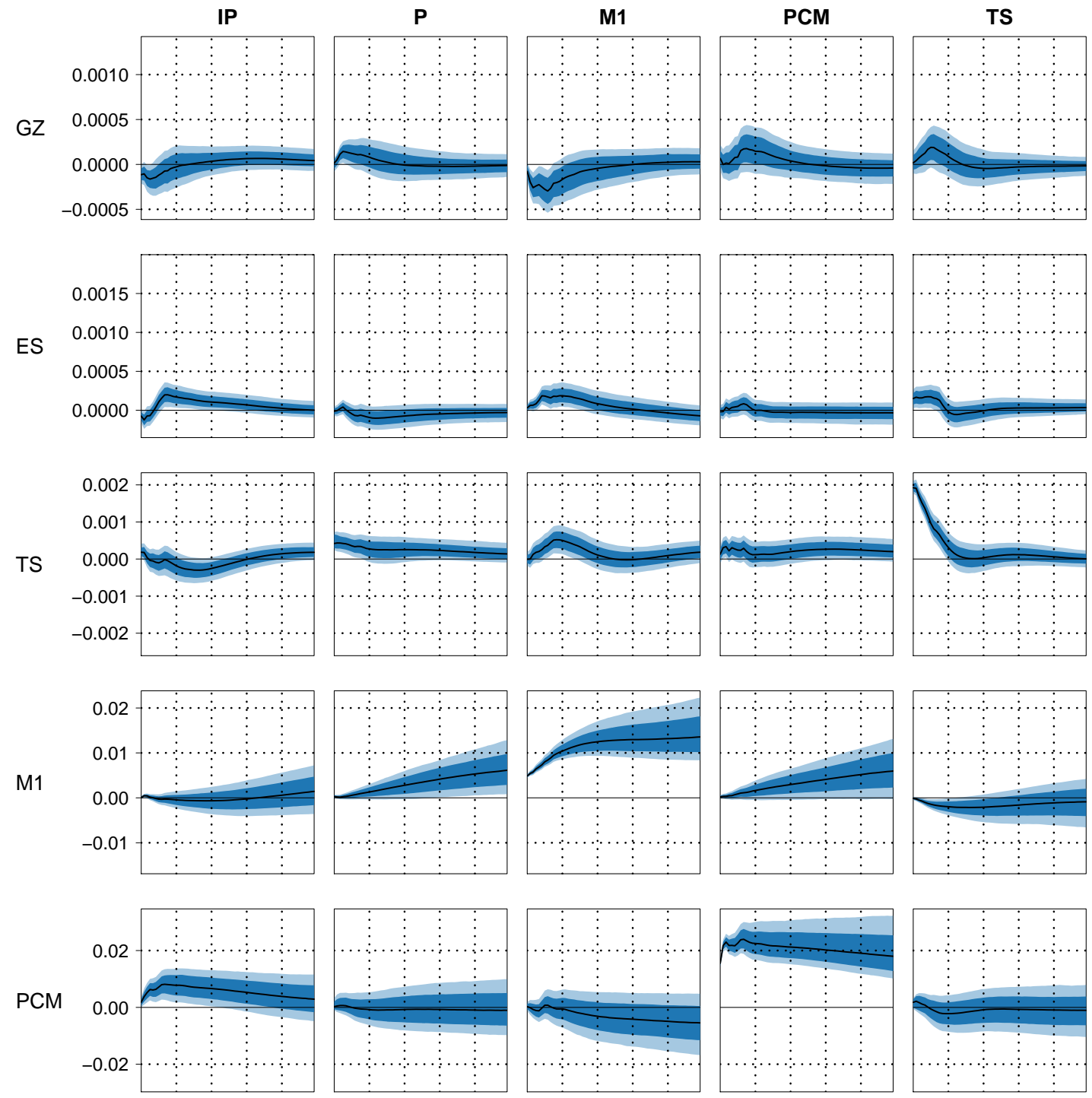

FIGURE 4. (4/4) Impulse responses to the ten orthogonal structural shocks in the model with $t$ distributed errors over 60 months, with 68\% (dark blue) and $90 \%$ (light blue) posterior uncertainty regions. Scaled to an "average" period with unit scale. 

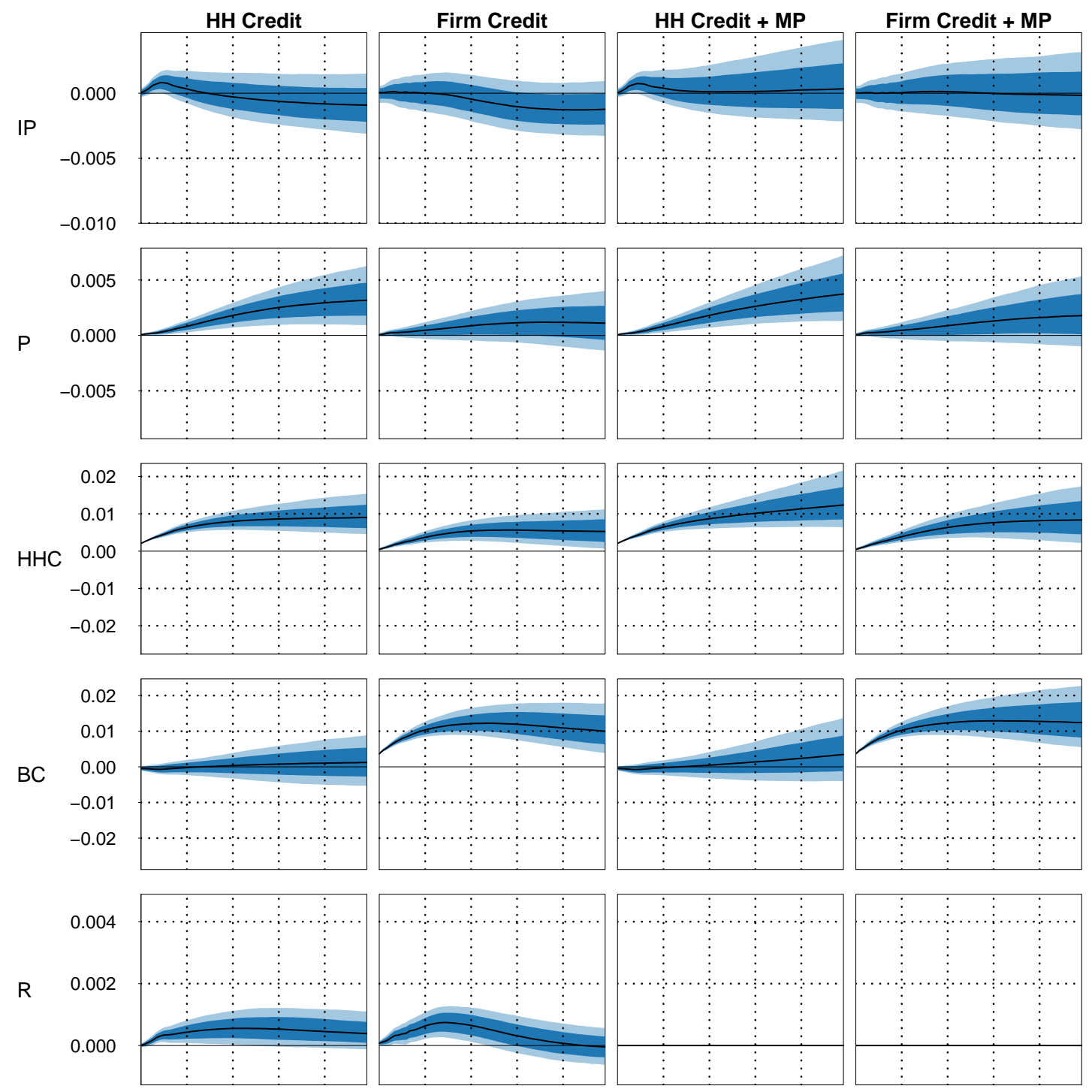

FIGURE 5. The first two columns reproduce the responses to the HHC and BC shocks in Figures 1 and 2. The third and fourth columns combine each shock with a series of shocks to he monetary policy shock, that keep R constant. 

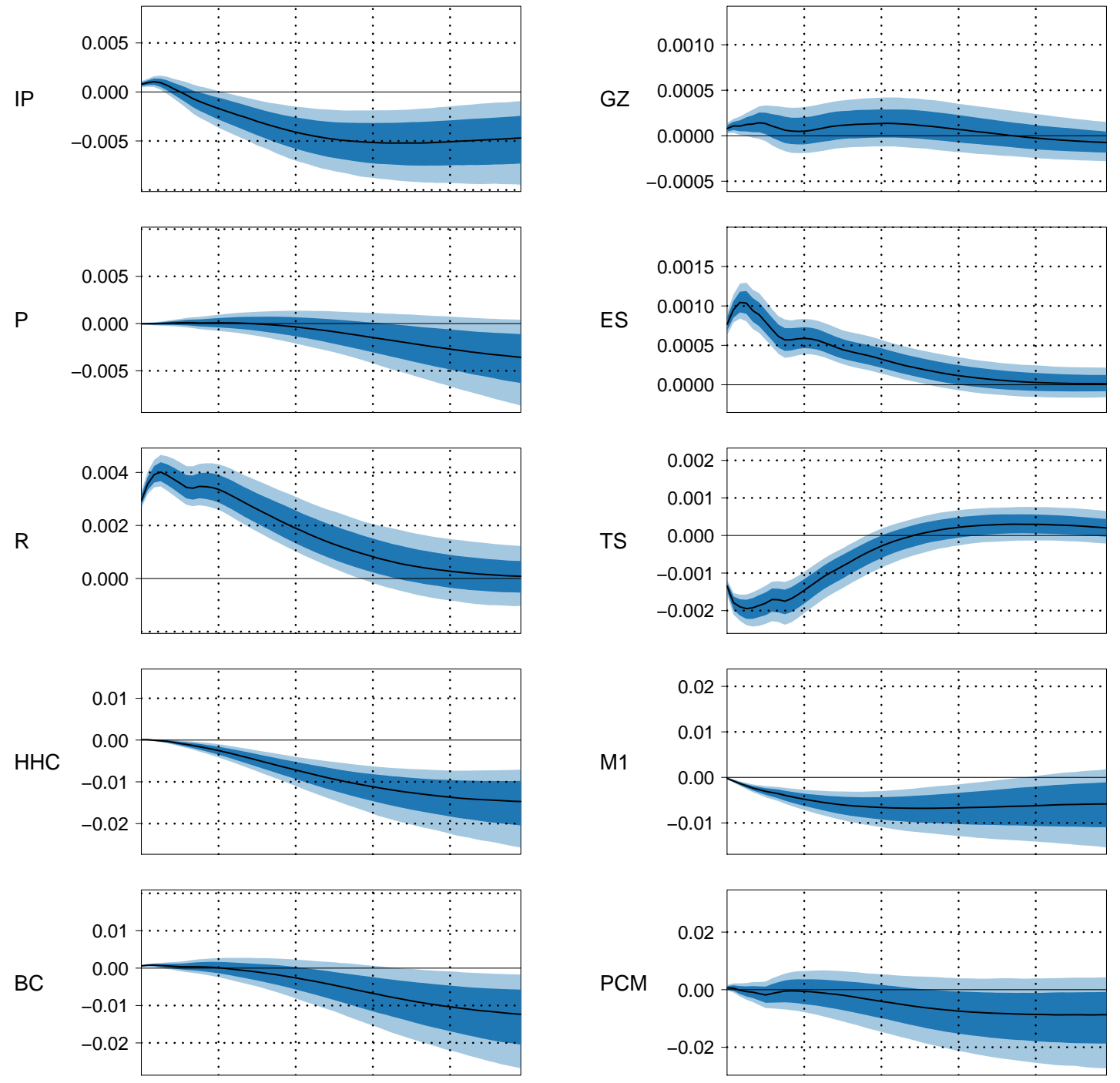

FIGURE 6. Impulse responses to the monetary policy shock, with $68 \%$ (dark blue) and $90 \%$ (light blue) posterior uncertainty regions. Scaled to an "average" period with unit scale. 
Figures
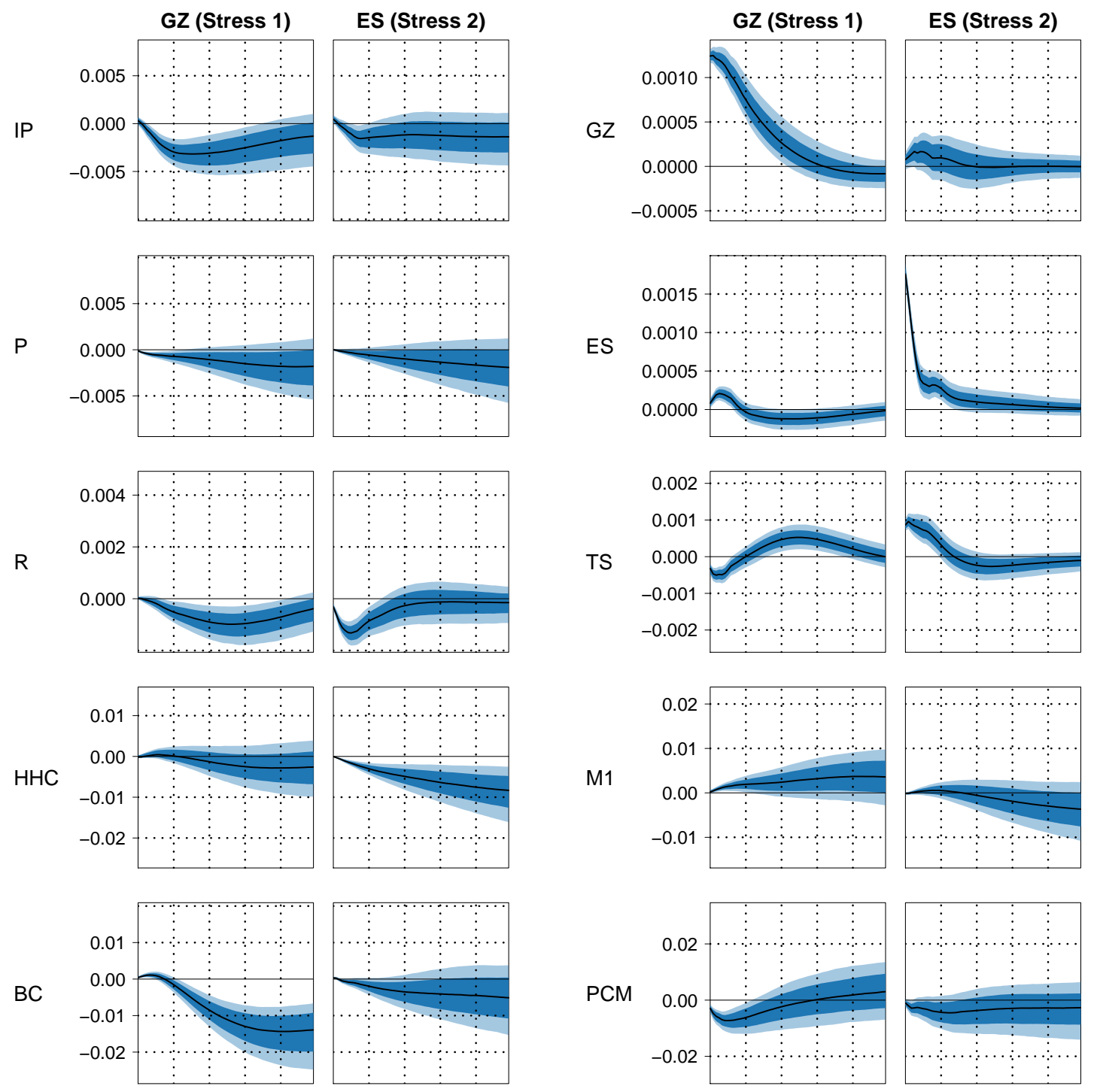

FIGURE 7. Impulse responses to the bond spread (GZ) and inter-bank spread (ES) shocks, with 68\% (dark blue) and 90\% (light blue) posterior uncertainty regions. Scaled to an "average" period with unit scale. 
Figures
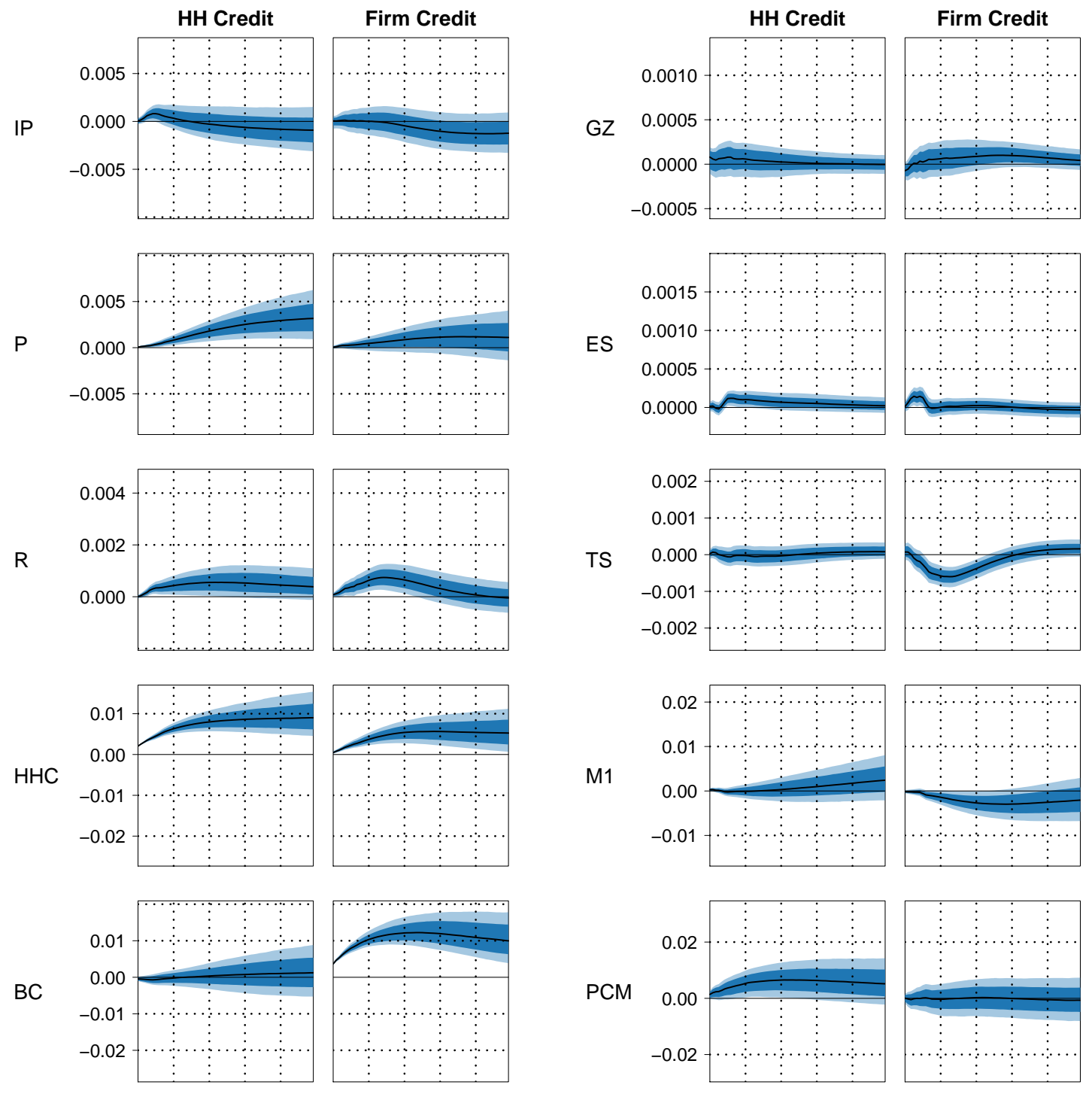

FIGURE 8. Impulse responses to the household credit (HHC) and firm credit (BC) shocks, with 68\% (dark blue) and 90\% (light blue) posterior uncertainty regions. Scaled to an "average" period with unit scale. 

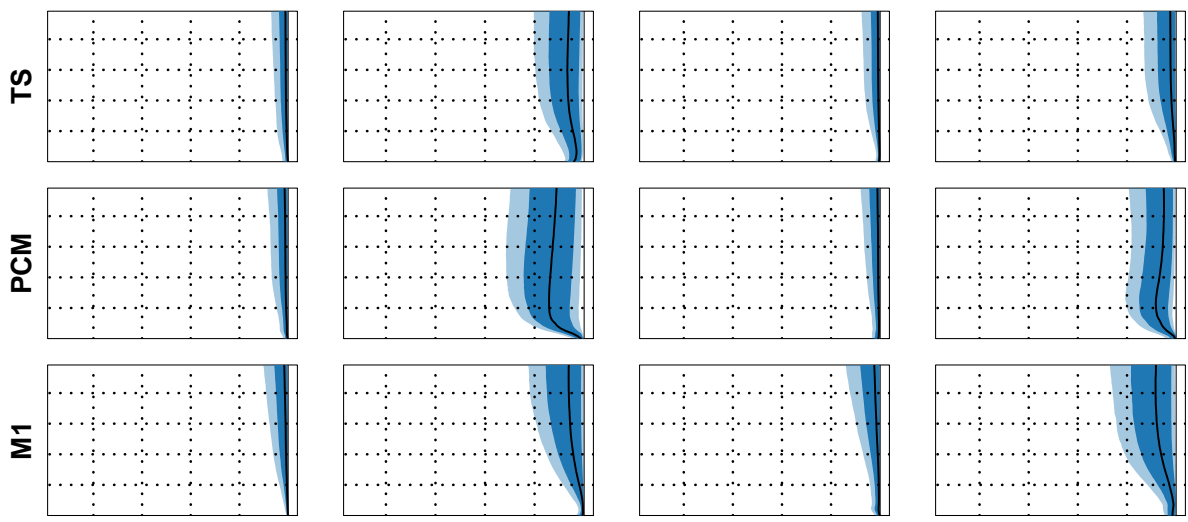

ฉ
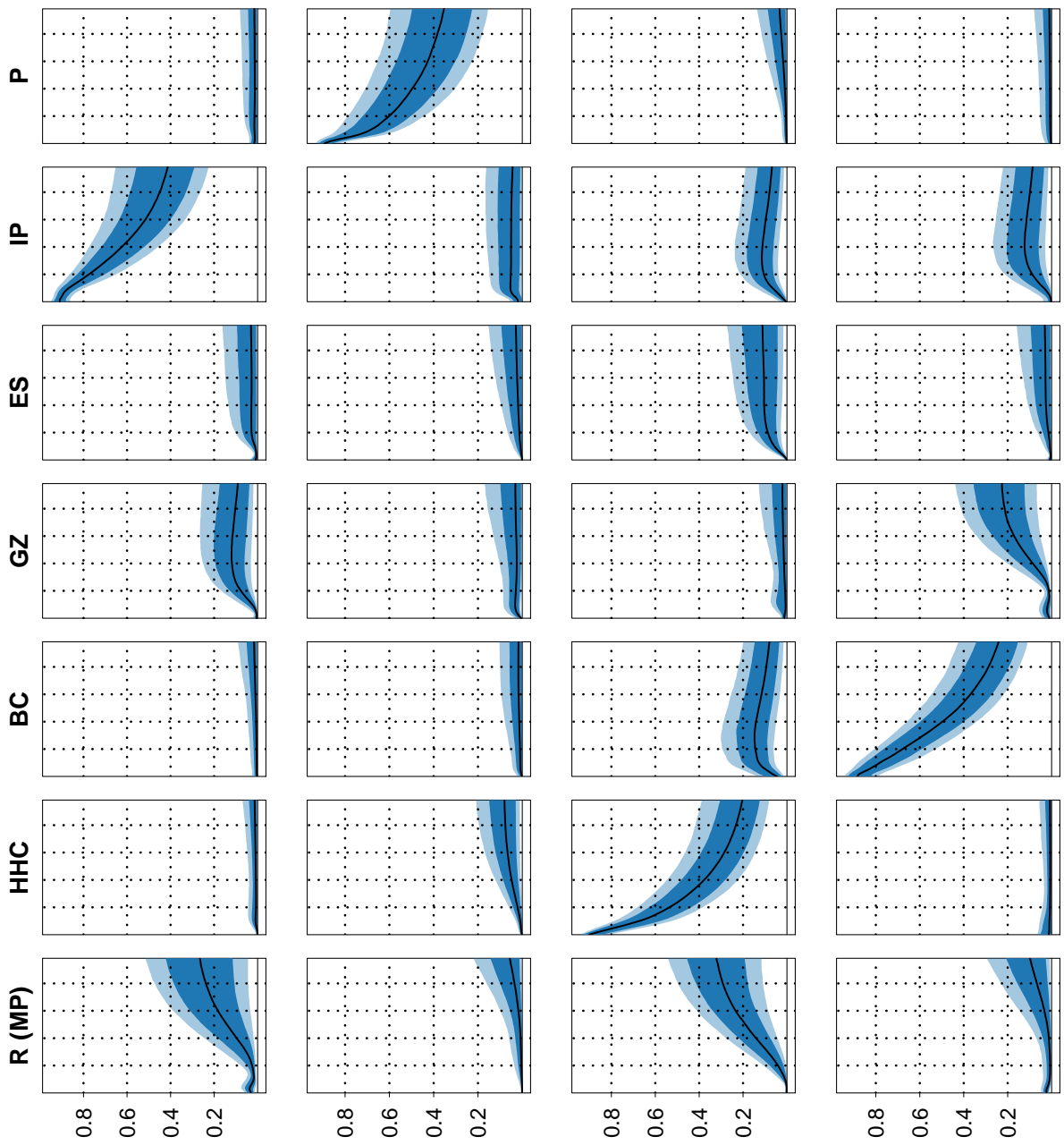

ㅇ

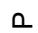

옴

o

FIGURE 9. Forecast variance decompositions in the $t$-distributed errors model for IP, prices, household credit, and business credit over 60 months, with $68 \%$ (dark blue) and 90\% (light blue) posterior uncertainty regions. Scaled to an "average" period with unit scale. Variables are in the order listed in Table 1. 

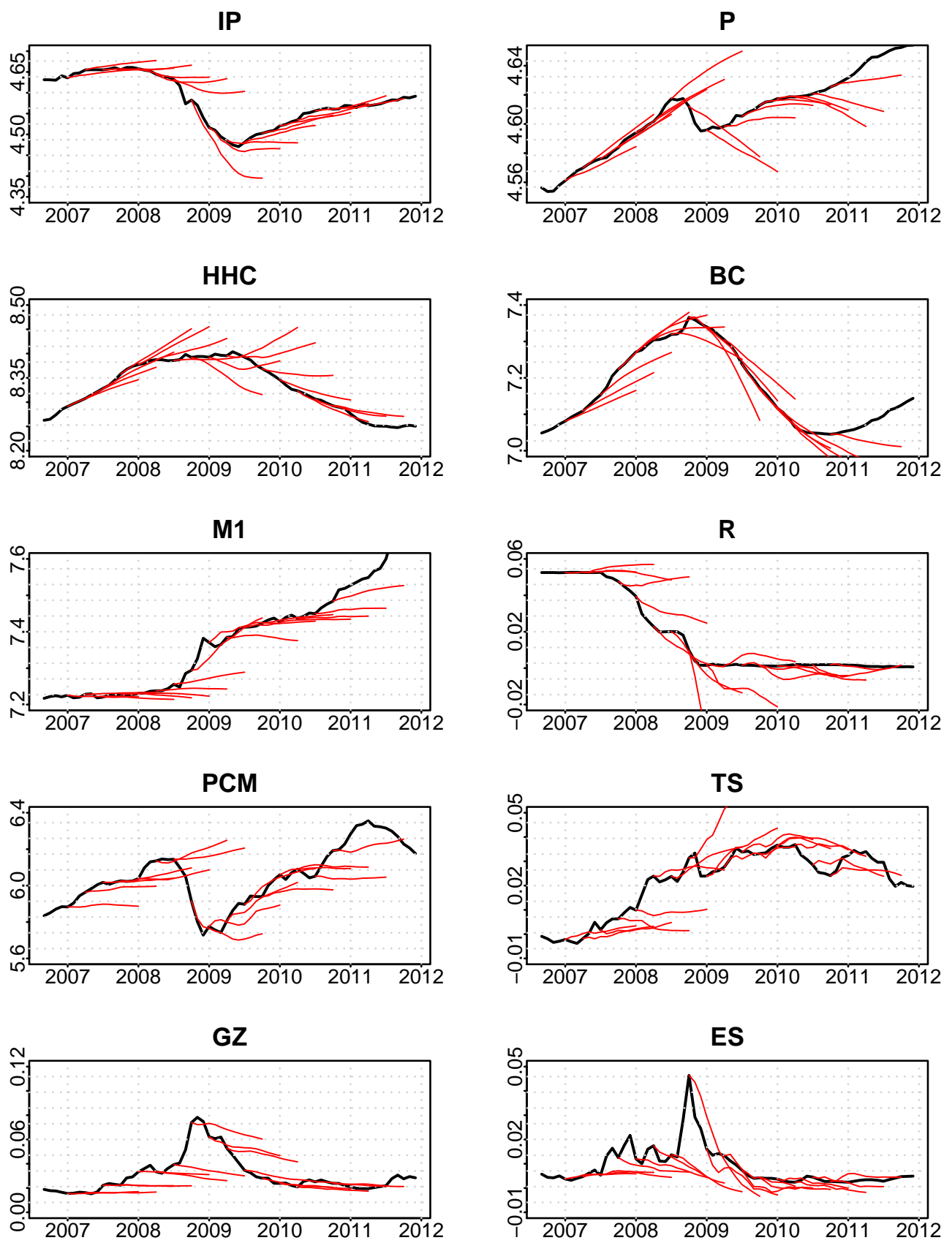

FIGURE 10. Posterior mode forecasts, from a model with all ten variables, estimated up to points in and around the Great Recession. 

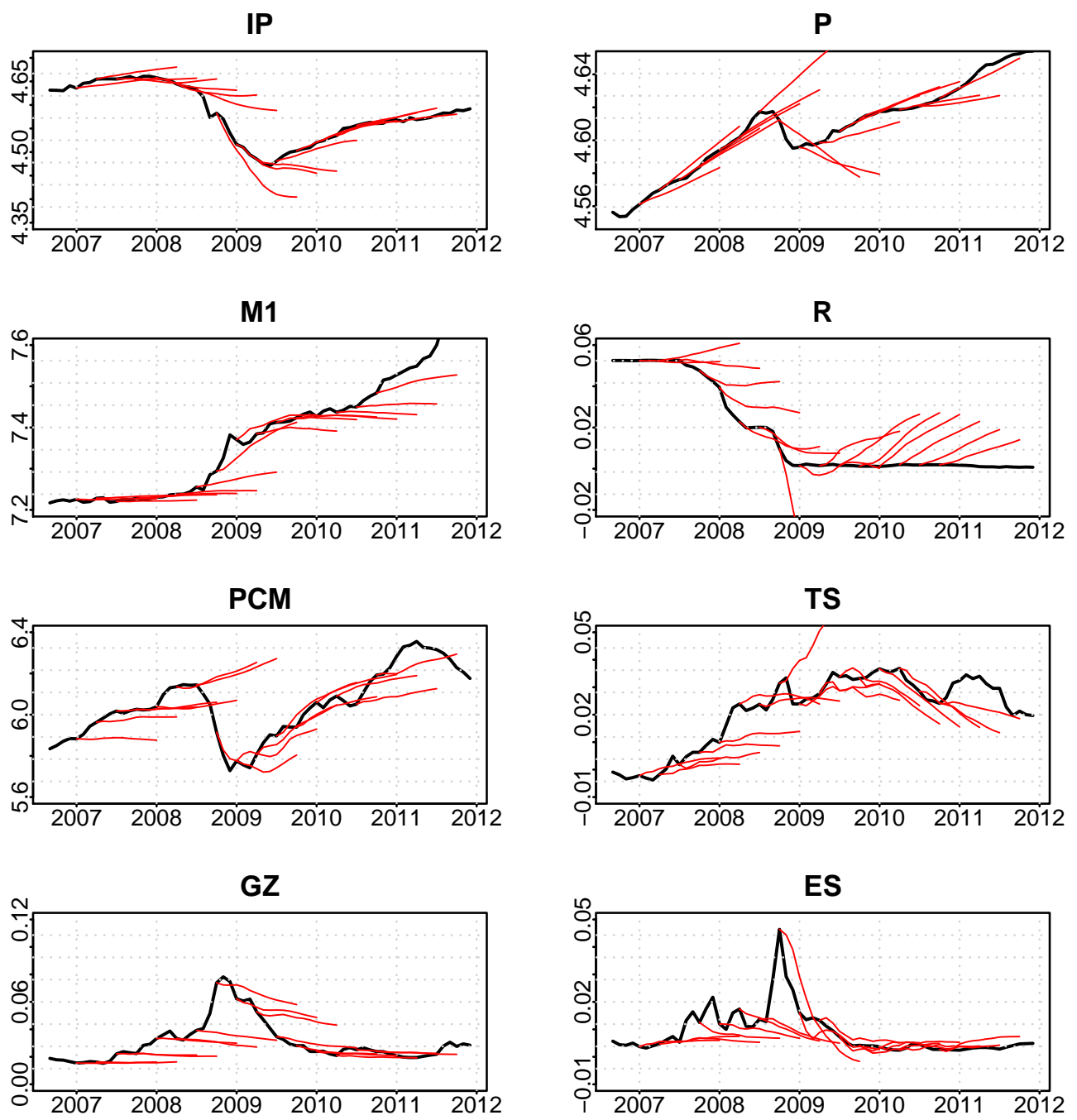

FIGURE 11. Posterior mode forecasts, from a model without the two credit aggregates, estimated up to points in and around the Great Recession. 

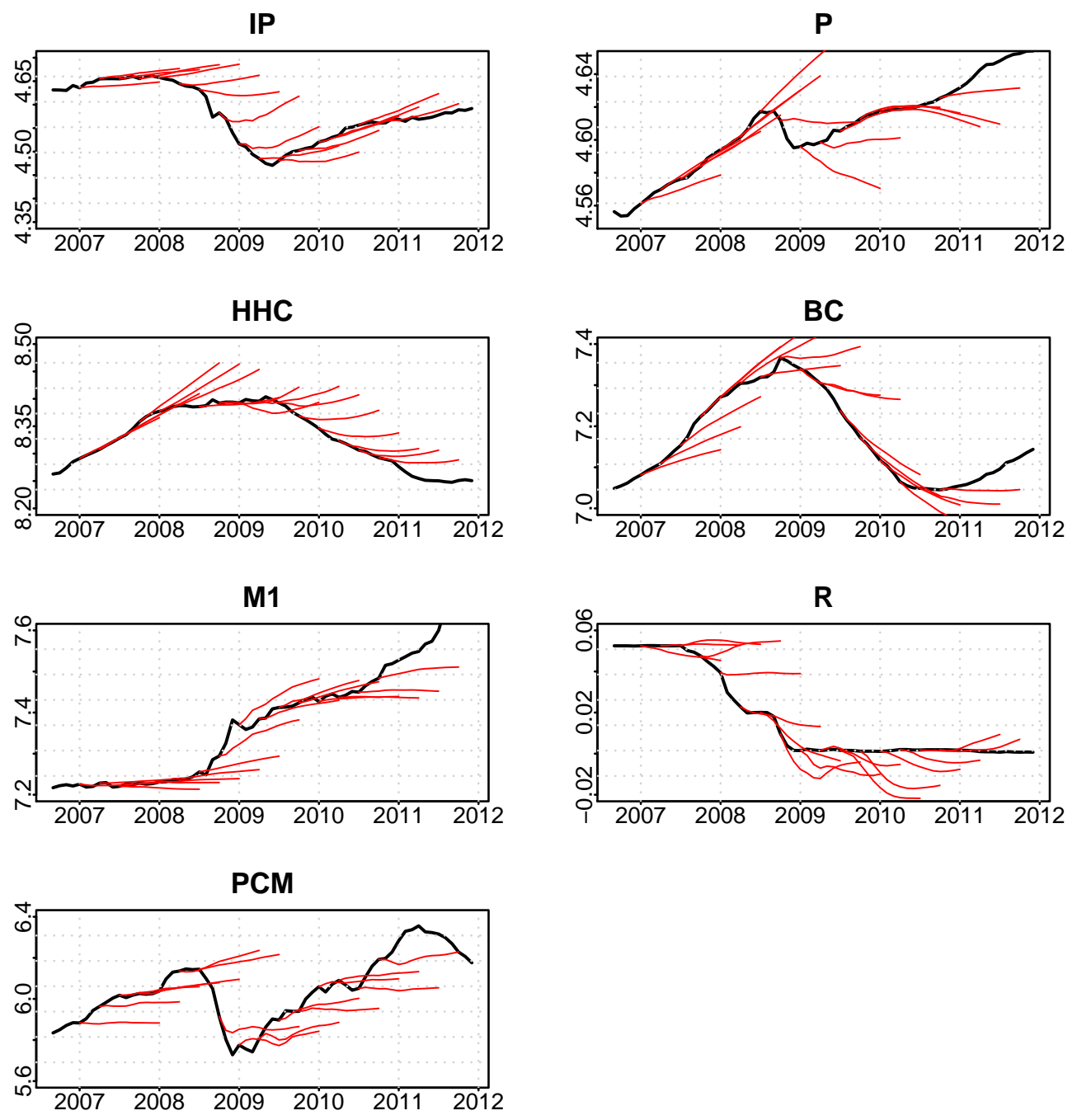

FIGURE 12. Posterior mode forecasts, from a model without the three credit spreads, estimated up to points in and around the Great Recession. 

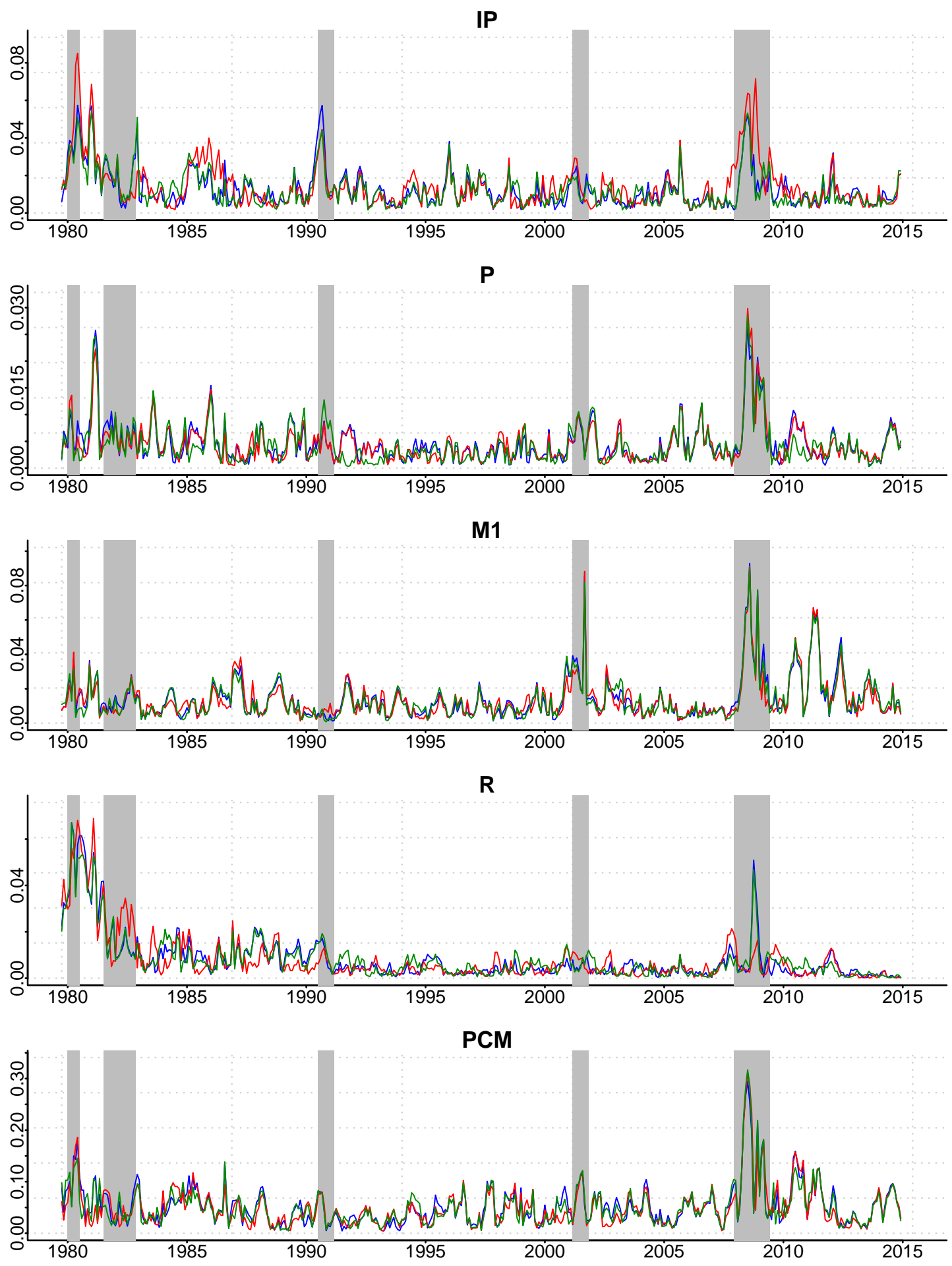

FIGURE 13. Root mean squared error (RMSE) for 6-month forecasts from rolling estimations of the Gaussian errors model with all variables (blue), no credit spreads (red), and no credit aggregates (green). NBER recessions are shaded. 

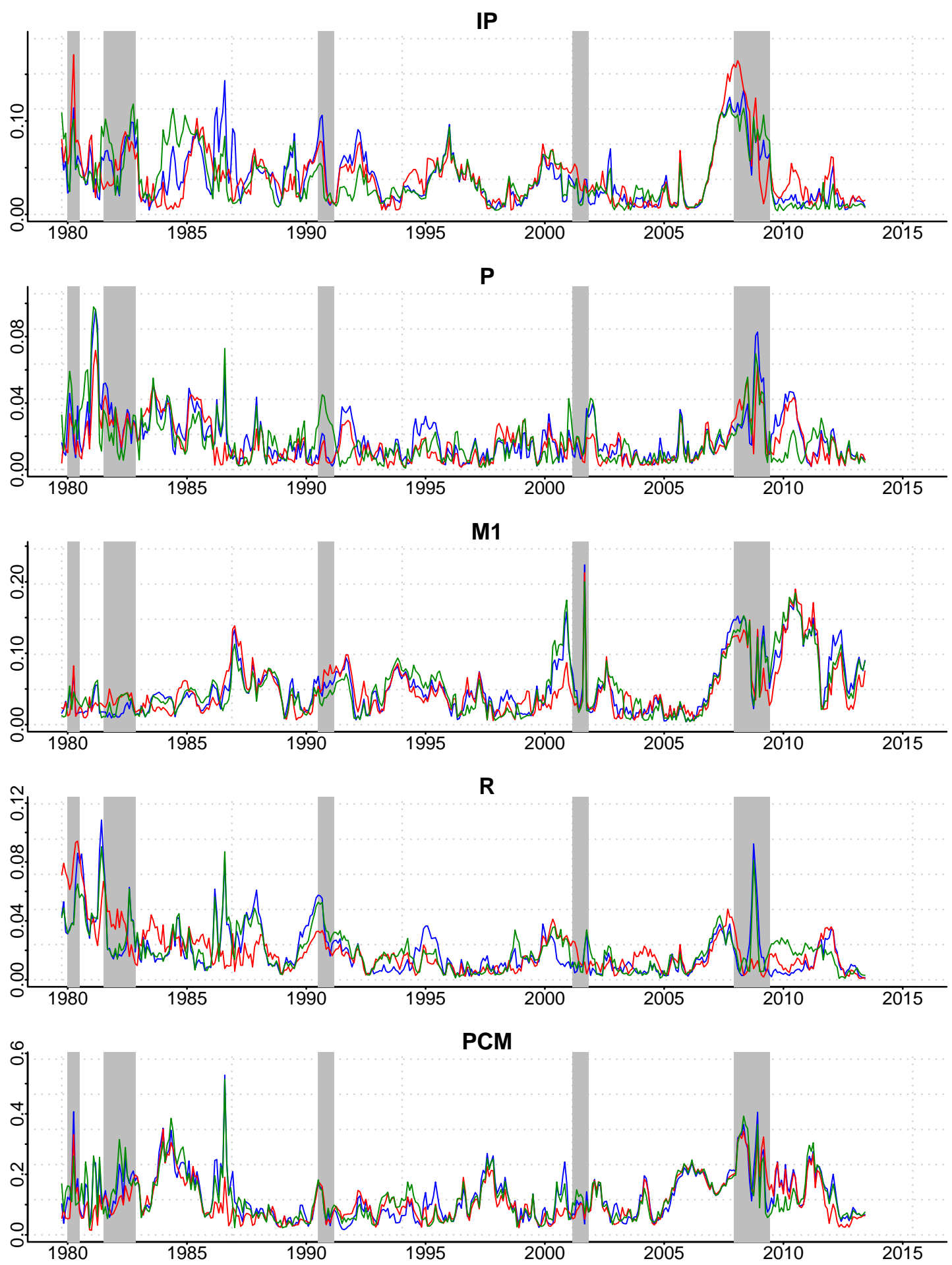

FIGURE 14. Root mean squared error (RMSE) for 24-month forecasts from rolling estimations of the main model with all variables (blue), no credit spreads (red), and no credit aggregates (green). NBER recessions are shaded. 